OPEN ACCESS

Edited by:

Chi-Kuang Wen,

Shanghai Institutes for Biological

Sciences (CAS), China

Reviewed by:

Jeremy Dale Murray,

John Innes Centre (BBSRC),

United Kingdom

Ertao Wang,

Institute of Plant Physiology and Ecology, Shanghai Institutes for Biological Sciences (CAS), China

*Correspondence:

Peizhu Guan

peguan@ucsd.edu

Specialty section:

This article was submitted to

Plant Physiology,

a section of the journal

Frontiers in Plant Science

Received: 30 June 2017 Accepted: 15 September 2017 Published: 28 September 2017

Citation:

Guan P (2017) Dancing with Hormones: A Current Perspective of Nitrate Signaling and Regulation in Arabidopsis.

Front. Plant Sci. 8:1697. doi: 10.3389/fpls.2017.01697

\section{Dancing with Hormones: A Current Perspective of Nitrate Signaling and Regulation in Arabidopsis}

\author{
Peizhu Guan* \\ Section of Cell and Developmental Biology, Division of Biological Sciences, University of California, San Diego, La Jolla, CA, \\ United States
}

In nature and agriculture, nitrate availability is a main environmental cue for plant growth, development and stress responses. Nitrate signaling and regulation are hence at the center of communications between plant intrinsic programs and the environment. It is also well known that endogenous phytohormones play numerous critical roles in integrating extrinsic cues and intrinsic responses, regulating and refining almost all aspects of plant growth, development and stress responses. Therefore, interaction between nitrate and phytohormones, such as auxins, cytokinins, abscisic acid, gibberellins, and ethylene, is prevalent. The growing evidence indicates that biosynthesis, de-conjugation, transport, and signaling of hormones are partly controlled by nitrate signaling. Recent advances with nitrate signaling and transcriptional regulation in Arabidopsis give rise to new paradigms. Given the comprehensive nitrate transport, sensing, signaling and regulations at the level of the cell and organism, nitrate itself is a local and long-distance signal molecule, conveying $\mathrm{N}$ status at the whole-plant level. A direct molecular link between nitrate signaling and cell cycle progression was revealed with TEOSINTE BRANCHED1/CYCLOIDEA/PROLIFERATING CELL FACTOR1-20 (TCP20) - NIN-LIKE PROTEIN 6/7 (NLP6/7) regulatory nexus. NLPs are key regulators of nitrogen responses in plants. TCPs function as the main regulators of plant morphology and architecture, with the emerging role as integrators of plant developmental responses to the environment. By analogy with auxin being proposed as a plant morphogen, nitrate may be an environmental morphogen. The morphogen-gradient-dependent and cell-autonomous mechanisms of nitrate signaling and regulation are an integral part of cell growth and cell identification. This is especially true in root meristem growth that is regulated by intertwined nitrate, phytohormones, and glucose-TOR signaling pathways. Furthermore, the nitrate transcriptional hierarchy is emerging. Nitrate regulators in primary nitrate signaling can individually and combinatorially control downstream transcriptional networks and hormonal pathways for signal propagation and amplification. Under the new paradigms, nitrate-induced hormone metabolism and signaling deserve fresh examination. The close interplay and convergent regulation of nitrate and hormonal signaling at morphological, physiological, and molecular levels have significant effects on important agronomic traits, especially nutrient-dependent adaptive root system growth and architecture. 


\section{INTRODUCTION}

As a constituent of amino acids and nucleotides, nitrogen $(\mathrm{N})$ is an essential building block for all forms of life. Not surprisingly, the mineral nutrient needed in greatest abundance by plants is $\mathrm{N}$ (Crawford, 1995). N availability is crucial for plant anabolism and catabolism. Despite the abundance of $\mathrm{N}(78 \%)$ in the atmosphere, the availability of fixed $\mathrm{N}$ in Earth's crust is scarce to such an extent that $\mathrm{N}$ is the quantitatively most limiting nutrient for plants (Vance, 2001; Miller and Cramer, 2004). In nature and agricultural systems, plants take up $\mathrm{N}$ mainly from soils in two forms, nitrate and ammonium, by roots during their postembryonic growth. Nitrate is the predominant form of $\mathrm{N}$ in aerobic soils where nitrification occurs rapidly (Crawford and Forde, 2002). As most soils on Earth are aerobic, nitrate is a primary $\mathrm{N}$ source and hence an essential nutrient for most plants.

Plants are sessile organisms that always face spatiotemporal fluctuations of nitrate concentrations in soil solution by up to four orders of magnitude due to leaching and microbial activity (Crawford, 1995; Vance, 2001; Miller and Cramer, 2004). In interacting with the environment, plants have evolved elaborate adaptive sensing, signaling and regulatory network in response to nitrate availability for survival, fitness and reproduction (Crawford, 1995; Wang et al., 2004, 2012; Remans et al., 2006a,b; Ho et al., 2009; Ruffel et al., 2011; Marchive et al., 2013; Guan et al., 2014, 2017; Vidal et al., 2015; Bellegarde et al., 2017; Liu et al., 2017). Nitrate is hence an essential nutrient as well as a crucial signal for plant growth, development, and stress responses.

Furthermore, nitrate and hormonal signaling and their interaction are of fundamental importance, underlying a plethora of plant physiological, morphological, and developmental processes in plants (Krouk et al., 2011; Nacry et al., 2013; Krapp, 2015; Krouk, 2016; O’Brien et al., 2016; Bellegarde et al., 2017). Much of our understanding of the process has been achieved so far by the molecular genetic studies using Arabidopsis thaliana as a model. The accumulating evidence indicates that biosynthesis, de-conjugation, degradation, transport, and signaling of hormones are partly controlled by nitrate signaling, so that the environmental and internal signaling pathways are seamlessly integrated.

Much of the literature on the interaction between nitrate and hormonal signaling pathways has been focused on hormonal control of nitrate metabolism and signaling (Kiba et al., 2010), while this review focuses more on the other side of the coin - nitrate signaling control of hormone metabolism and signaling (Krouk, 2016). The latest findings in nitrate research revealed novel molecular links between $\mathrm{N}$ and plant development (Ristova et al., 2016; Guan et al., 2017; Liu et al., 2017) shed new light on nitrate-hormone interconnections. In the context of agronomy, nitrate- and hormone-regulated lateral root (LR) growth and development are among the main determinants of root plasticity in response to nitrate availability and of nitrogen use efficiency (NUE) in crops. Therefore, the interplay and convergent regulation of nitrate and hormones in LR, which is highlighted in this review, is of agronomic importance.

\section{NITRATE SIGNALING, UNCOUPLED FROM NITRATE METABOLISM, ACTS AT LOCAL AND WHOLE-PLANT LEVELS}

Nitrate is taken up by roots then transported into root and shoot cells mainly via the NITRATE TRANSPORTER 1 (NRT1) and NITRATE TRANSPORTER 2 (NRT2) family of nitrate transporters (Wang et al., 2012). Once inside the cells, nitrate is reduced to nitrite by NITRATE REDUCTASE (NR) in the cytosol. In $A$. thaliana, two NR enzymes, NIA1 and NIA2, are responsible for 10 and $90 \%$ of the total NR activity in seedlings, respectively (Cheng et al., 1988; Wilkinson and Crawford, 1991, 1993). Nitrite is then reduced to ammonium by NITRITE REDUCTASE (NiR) in plastids, where ammonium is in turn assimilated into glutamine (Gln) (Crawford, 1995). Notably, with external nitrate concentration increases, nitrate assimilation into amino acids in higher plants is increasingly achieved in shoots, which become the main sites of NR activity (Andrews, 1986). In addition to amino acids production, nitrate metabolism supports plant use of light, $\mathrm{CO}_{2}$ and water to produce sugars and organic acids. In spite of its importance, nitrate assimilation is energetically costly, demanding intensive use of adenosine triphosphate (ATP), reducing equivalents, and C skeletons (Nunes-Nesi et al., 2010). Therefore, nitrate assimilation is subject to restraint or stimulation by resource availability in the environment and the demands of plant growth and development.

Fundamentally, nitrate signaling is uncoupled from, but executes tight control over, nitrate metabolism (Wang et al., 2000, 2003, 2004, 2007, 2009; Scheible et al., 2004; Muños et al., 2004; Ho et al., 2009; Nunes-Nesi et al., 2010; Konishi and Yanagisawa, 2013; Marchive et al., 2013; Bouguyon et al., 2015; Guan et al., 2017; Liu et al., 2017). Most plants have been wired to perceive nitrate, but not its downstream metabolites, e.g., ammonium and Gln, as the principal source of $\mathrm{N}$ offered by the environment. Among the earliest and most convincing evidence is that revealed by transcriptome analysis in NR-null (nia1 nia2) mutants, numerous genes, including the key nitrate assimilatory genes, directly respond to nitrate independent of nitrate reduction (Wang et al., 2004). Hence, nitrate is a signal molecule of paramount importance, from stimulating germination, to sustaining substantial postembryonic growth, to controlling developmental phase transitions (Alboresi et al., 2005; Chopin et al., 2007; Fan et al., 2009; Nunes-Nesi et al., 2010; Vidal et al., 2014b; Yan et al., 2016; Guan et al., 2017; Liu et al., 2017). In response to soil nitrate availability, plants reprogram genomewide short-term and long-term gene expression at the wholeplant level and promote adaptive regulation of organogenesis, involving root system architecture, root and shoot growth, leaf expansion, flowering time, stomata opening, defense responses, etc. (Forde, 2002; Walch-Liu et al., 2005; Krouk et al., 2010a; Castro-Marín et al., 2011; Ruffel et al., 2011; Fagard et al., 2014; Guan et al., 2014, 2017; Liu et al., 2017). 
When exposed to nitrate, the first, and also one of the foremost nitrate responses in plants that has been extensively studied is the primary nitrate response (PNR) (Redinbaugh and Campbell, 1991; Wang et al., 2000, 2003, 2004, 2007; Scheible et al., 2004; Medici and Krouk, 2014; Ristova et al., 2016). The PNR is rapid, independent of de novo protein synthesis, and responsive to nitrate concentrations as low as $100 \mathrm{nM}$ in roots and $250 \mu \mathrm{M}$ in shoots of pre-starved Arabidopsis seedlings. The PNR affects the expression of 1,596 genes at the significance level in wild-type (WT) plants. Among those genes, 595 genes in both roots and shoots directly responded to nitrate, which is confirmed in the NR-null mutant (nia1 nia2) (Wang et al., 2004).

Indeed, the nitrate response is a whole-plant response and nitrate itself can function as both a local and long-distance systemic signal (Wang et al., 2004; Ruffel et al., 2011). The phenomenon was initially revealed by microarray analysis of nitrate-regulated gene expression in roots and shoots of the seedlings that were grown hydroponically. When treated with $0.25 \mathrm{mM}$ nitrate for only $20 \mathrm{~min}$, the roots have a much broader response than shoots in terms of the number of genes being affected (Wang et al., 2000). However, with sufficient nitrate concentrations and sufficient time $(5 \mathrm{mM}$ nitrate for $2 \mathrm{~h}$ ) for nitrate transport facilitation (but not for reduction), the shoot genes in the NR-null mutant can be as responsive to nitrate as root genes, although the two groups of genes are still organ-specific (Wang et al., 2004). The PNR genes in roots and shoots are selectively targeted, with an overall concentration on energy and metabolism, including glycolysis and gluconeogenesis, amino acid metabolism, nitrogen and sulfur utilization, and transport facilitation (Wang et al., 2004); nevertheless, there are also a large group of genes for signaling and regulatory components intimately related to the twocomponent systems (TCS), calcium and sugar transport, auxin, cytokinins, and abscisic acid (ABA) metabolism and signaling, and so on (Wang et al., 2000, 2003, 2004; Ristova et al., 2016; Liu et al., 2017).

Nitrate signaling and regulation underlie the genome-wide expression reprogramming in nitrate responses, which leads to activation and adaptation of N-regulated metabolism and development. The process involves membrane and cytosol sensing, signal transduction, transcription factors (TFs), the interactions of TFs, and nitrate-responsive DNA regulatory elements (Ho et al., 2009; Wang et al., 2010; Guan et al., 2014, 2017; Liu et al., 2017). On the other hand, the transcriptome analysis revealed that numerous pathways and processes, particularly hormone signaling pathways, have interaction with and depend on nitrate signaling (Krouk, 2016; O'Brien et al., 2016; Ristova et al., 2016) for N status before making collective decisions in growth, development and stress responses.

\section{NITRATE TRANSPORT, SIGNALING AND REGULATION AT A GLANCE}

In plants, the first identified and characterized nitrate transporter is known as chlorate resistant 1 (CHL1) or AtNRT1.1 or AtNPF6.3 (Tsay et al., 1993). It is also the first plant member of NITRATE TRANSPORTER 1/PEPTIDE TRANSPORTER (NRT1/PTR) Family (also named NPF) discovered. The NRT1/PTR Family (NPF) comprises of membrane proteins ubiquitously found across all major kingdoms of life and sharing sequence homology. In bacteria, fungi, animals and plants, the family members were found to transport dipeptides (Leran et al., 2014; von Wittgenstein et al., 2014). In higher plants, there are at least four families of nitrate transporters. Besides NRT1/PTRs, the other three families are: NITRATE TRANSPORTER 2 (NRT2), CHLORIDE CHANNEL (CLC) a/b, and SLOW ANION CHANNEL-ASSOCIATED 1 HOMOLOG 3 (SLAH3) (Wang et al., 2012; Krapp et al., 2014).

The nitrate transporters contribute to numerous physiological functions involved in different stages and processes of nitrate distribution, assimilation, signaling, and osmotic regulation. They are individually critical, such as NRT1.1 (CHL1/NPF6.3), NRT1.2 (NPF4.6/AIT1), NRT2.1, NRT2.2, NRT2.4, and NRT2.5 in nitrate uptake from soil (Tsay et al., 1993; Huang et al., 1999; Cerezo et al., 2001; Kiba et al., 2012; Lezhneva et al., 2014); NAXT1 (NPF2.7) in nitrate efflux (Segonzac et al., 2007); NRT1.5 (NPF7.3), NRT1.8 (NPF7.2), and NRT1.9 (NPF2.9) in root-to-shoot xylem translocation, a primary route of longdistance nitrate transport driven by transpiration, which is accompanied by shoot-to-root xylem and phloem transport of nitrate (Lin et al., 2008; Li et al., 2010; Wang and Tsay, 2011); NRT1.7 (NPF2.13), NRT1.9 (NPF2.9), NRT2.4 and NRT2.5 in source-to-sink phloem remobilization, a secondary route of long-distance nitrate transport driven by osmotic gradients in both roots and shoots (Fan et al., 2009; Wang and Tsay, 2011; Kiba et al., 2012; Lezhneva et al., 2014); NRT1.4 (NPF6.2) in nitrate petiole storage (Chiu et al., 2004); CLCa/b in nitrate accumulation in vacuoles (De Angeli et al., 2006; von der FechtBartenbach et al., 2010); NRT1.6 (NPF2.12) and NRT2.7 in nitrate accumulation in seeds (Chopin et al., 2007; Almagro et al., 2008); NRT1.1 (CHL1/NPF6.3) and SLAH3 in stomatal closure and opening (Guo et al., 2003; Geiger et al., 2011); NRT1.11 (NPF1.2) and NRT1.12 (NPF1.1) in xylem-to-phloem transfer for redistributing nitrate (Hsu and Tsay, 2013); NPF2.3 in nitrate translocation to shoots for acclimation to salt stress (Taochy et al., 2015); and NPF5.5 in embryo N accumulation (Leran et al., 2015) (Figure 1). All transport proteins are localized at the plasma membrane, except that NRT2.7 and CLCa/b are localized at the tonoplast (Wang et al., 2012; O’Brien et al., 2016).

As a result of dramatic fluctuations of nitrate concentrations in soil, plants have evolved two uptake systems: low-affinity transport system (LATS) for high external nitrate concentration $(>0.5 \mathrm{mM})$ and high-affinity transport system (HATS) for low nitrate concentration $(<0.5 \mathrm{mM})$, into which most nitrate transporters in roots and shoots can be categorized (Crawford and Glass, 1998; Forde, 2000; Miller et al., 2007). All known NPF transporters, except NRT1.1 (CHL1/NPF6.3), solely belong to LATS. Even though a majority of low- and high-affinity transporters are inducible, the two exceptions are NRT2.5 in HATS and NRT1.2 (NPF4.6/AIT1) in LATS, which are constitutive nitrate transporters (Huang et al., 1999; Lezhneva et al., 2014; Kotur and Glass, 2015). This gave rise to the four subsystems: the constitutive high-affinity system (cHATS), the 


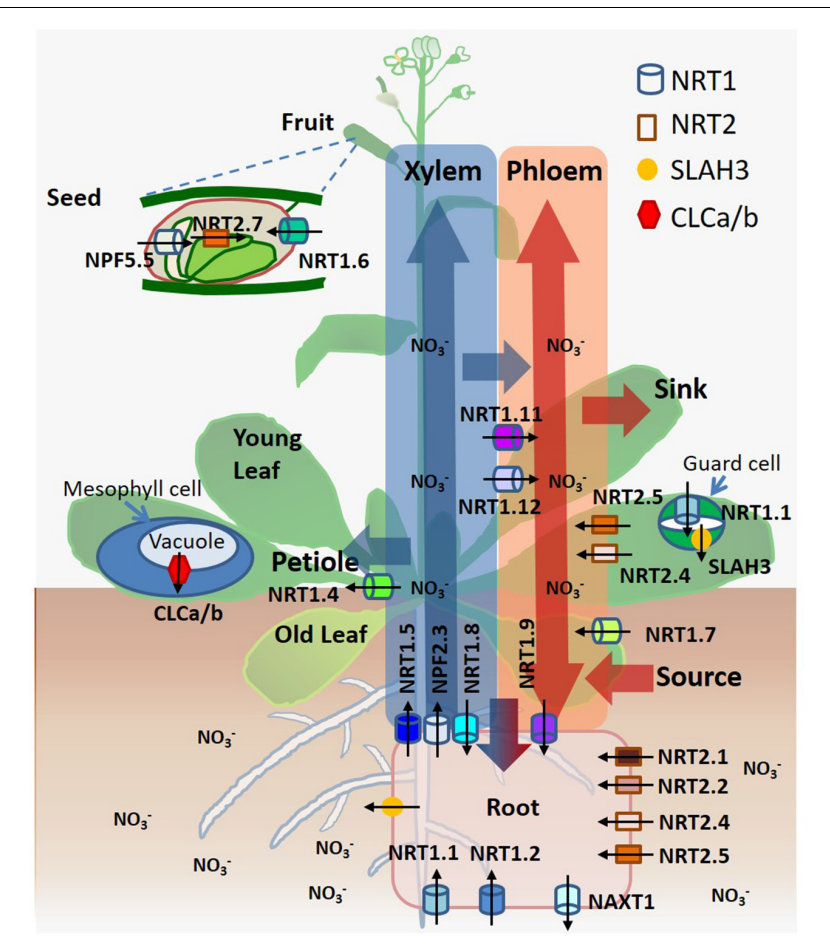

FIGURE 1 | A summary of spatiotemporal functionality of nitrate transporters/channels and nitrate transport routes in Arabidopsis. Nitrate is taken up by roots, loaded/unloaded by xylem and phloem, and transported to leaves, shoots and seeds. Arrows indicate the directions of nitrate movement. Transporters and channels are depicted according to their localization.

inducible high-affinity system (iHATS), the constitutive lowaffinity system (cLATS), and the inducible low-affinity system (iLATS) (Crawford and Glass, 1998; Forde, 2000; Tsay et al., 2007). Much attention has been given to the nitrate transporters that play crucial roles of mineral uptake in roots, the principal nutrient absorbing organs. In Arabidopsis roots, LATS involves NRT1.1 (CHL1/NPF6.3) and NRT1.2 (NPF4.6/AIT1) (Tsay et al., 1993; Huang et al., 1999), and HATS involves NRT1.1 (CHL1/NPF6.3), NRT2.1, NRT2.2, NRT2.4, and NRT2.5 (Wang et al., 1998; Liu et al., 1999; Cerezo et al., 2001; Li et al., 2007; Kiba et al., 2012; Lezhneva et al., 2014; Kotur and Glass, 2015). The NRT1s and NRT2s are both proton-coupled transporters. The interaction with NAR2 is critical for transport capacity of most high-affinity NRT2s in plants (Kotur et al., 2012; Kotur and Glass, 2015). When root epidermal cells are exposed to nitrate, the $\mathrm{H}^{+}$-ATPase in the plasma membrane pumps protons out of the cell, producing $\mathrm{pH}$ and electrical $(\Delta \Psi)$ gradients, which potentially provides required energy to both LATS and HATS for co-transporting two or more protons per nitrate into the cell, a process also involving membrane depolarization. Both nitrate influx and efflux could be mediated by the proton-coupled mechanism (Crawford, 1995; Forde, 2000; Tsay et al., 2007; Wang et al., 2012).

Among the nitrate transporters so far characterized in Arabidopsis, NRT1.1 (CHL1/NPF6.3) is the only dual-affinity transporter (Wang et al., 1998; Liu et al., 1999; Liu and Tsay,
2003), although dual-affinity transport activity was also found in the potassium transporter AtKUP (Fu and Luan, 1998; Kim et al., 1998) and the nitrate transporter MtNRT1.3 (Morère-Le Paven et al., 2011). Moreover, NRT1.1 (CHL1/NPF6.3) mediates the expression of NRT2.1 and NRT3.1/ NAR2.1, depending on nitrate/ammonium concentrations. The process is the critical regulation of HATS, which is also under the feedback repression by $\mathrm{N}$ metabolites (Muños et al., 2004; Krouk et al., 2006). Tightly regulated by nitrate signaling, NRT1.1 (CHL1/NPF6.3) and NRT2.1 are most transcriptionally abundant (Wang et al., 2012). Beyond being transporters, they are also deeply involved in sensing and activating downstream gene expression, including the PNR and nitrate-regulated root development (Little et al., 2005; Remans et al., 2006a,b; Ho et al., 2009; Gojon et al., 2011).

Nitrate uptake, sensing and signaling are regulated by multiple mechanisms, which mainly include nitrate availability, feedback repression by $\mathrm{N}$ status, stimulation by photosynthesis, and hormone signaling (Forde, 2000; Wang et al., 2000, 2003, 2004, 2007; Nacry et al., 2013; Krouk, 2016; O’Brien et al., 2016). Significantly, primary nitrate signaling in response to nitrate availability is amplified and propagated overriding feedback constraints from downstream $\mathrm{N}$ metabolites and low sugars (Wang et al., 2004, 2007; Nunes-Nesi et al., 2010; Guan et al., 2017; Liu et al., 2017). The homeostasis of nitrate concentration, calcium, $\mathrm{pH}$, redox, and phosphate in the cytosol is delicately regulated and maintained in all cells, for which nitrate availability is a critical determinant. For instance, the steady-state cytosolic nitrate concentrations in barley root cells were recorded between 3 and $5 \mathrm{mM}$, which corresponds with a potential "optimal" range of exogenous nitrate concentrations (1-10 mM) for plants (Miller and Smith, 1996, 2008), and cytosolic $\mathrm{pH}$ varies from 7.3 to 8 in plants (Martinière et al., 2013). Among the primary signaling roles of nitrate is that the disruption of cytosolic ionic environment resulting from nitrate availability/unavailability and nitrate concentrations outside of the potential "optimal" range can trigger multiple downstream cascades of N-regulated events (Champigny and Foyer, 1992; Fan et al., 2016; Liu et al., 2017; Xuan et al., 2017). The nitrate-induced disruptions are rapidly captured by the evolutionarily conserved calcium signaling. The patterns of calcium level increase are elicited by nitrate in a context-dependent manner and calcium is specifically involved in the nitrate response and signaling as a modulator and/or a second messenger (Wang et al., 2000, 2003, 2004; Riveras et al., 2015; Liu et al., 2017).

In response to low exogenous nitrate concentration $(<1 \mathrm{mM})$, NRT1.1 $1^{\text {T101 }}$ phosphorylation is switched on, involving the CBLinteracting protein kinase CIPK23, a plant-specific calcium sensor (Ho et al., 2009; Hu et al., 2009). Through its dual-affinity binding and a phosphorylation-controlled dimerization switch between the two affinities, NRT1.1 (CHL1/NPF6.3) functions as a nitrate membrane sensor required for the PNR and other nitrate responses, independent of its uptake function as a transporter (Remans et al., 2006b; Ho et al., 2009; Wang et al., 2009). NRT1.1 (CHL1/NPF6.3) is regarded as the first transceptor discovered in plants by analogy with yeast nutrient transceptors (Ho et al., 2009; Gojon et al., 2011). It is a dose-dependent master controller of multiple signaling mechanisms capable of 
responding to a wide range of soil nitrate levels (Ho et al., 2009; Krouk et al., 2010a,b; Bouguyon et al., 2015; Leran et al., 2015). Nevertheless, prolonged $\mathrm{N}$ starvation rendered the nitrate response NRT1.1 (CHL1/NPF6.3) independent, suggesting alternative or redundant nitrate membrane sensing systems must be present (Wang et al., 2009). NRT2.1 has been proposed as such a candidate, which shows an uncoupled dual (uptake/signaling) function in root growth in response to nitrate availability (Remans et al., 2006a).

Although not capable of evoking the PNR per se, subgroup III calcium-dependent protein kinases (CPKs), CPK10, CPK30, and CPK32 are also required for rapid nitrate-induced cellular and metabolic responses, and nitrate-regulated root and shoot growth (Liu et al., 2017). In response to nitrate availability, $\mathrm{Ca}^{2+}$-sensor CPKs translocate to the nucleus, where the phosphorylation of $\mathrm{NLP}^{\mathrm{S} 205}$ by CPK10 is responsible for nitrate-stimulated nuclear retention of NLP7 (Liu et al., 2017). The widely overlapped transcriptomic and phenotypic defects in icpk and nlp7 mutants further substantiate the existence of the nitrate-CPK-NLP signaling-regulatory pathway potentially activating the downstream nitrate transcriptional network for signal amplification (Liu et al., 2017). Nevertheless, multiple sensing and signaling mechanisms with redundancy are synergically required for the context-dependent broad-ranged nitrate responses (Wang et al., 2009; Guan et al., 2017; Liu et al., 2017).

Furthermore, nitrate-responsive DNA regulatory elements (Girin et al., 2007; Konishi and Yanagisawa, 2010; Wang et al., 2010) and transcriptional regulators, including ARABIDOPSIS NITRATE REGULATED 1 (ANR1), NLP6, NLP7, LOB DOMAINCONTAINING PROTEIN 37/38/39 (LBD37/LBD38/LBD39), SQUAMOSA PROMOTER BINDING PROTEINLIKE 9 (SPL9), HIGH NITROGEN INSENSITIVE 9 (HNI9), NAC DOMAINCONTAINING PROTEIN 4 (NAC4), BASIC LEUCINE-ZIPPER 1 (bZIP1), TGACG MOTIF-BINDING FACTOR 1/4 (TGA1/TGA4), TCP20, HYPERSENSITIVE TO LOW PI-ELICITED PRIMARY ROOT SHORTENING 1 (HRS1), NITRATE REGULATORY GENE2 (NRG2), BRIC-A-BRAC/TRAMTRACK/BROADCOMPLEX 1/2 (BT1/BT2), and NLP8; (Zhang and Forde, 1998; Castaings et al., 2009; Rubin et al., 2009; Krouk et al., 2010c; Widiez et al., 2011; Konishi and Yanagisawa, 2013; Marchive et al., 2013; Alvarez et al., 2014; Guan et al., 2014, 2017; Para et al., 2014; Vidal et al., 2014b; Medici et al., 2015; Araus et al., 2016; Xu et al., 2016; Yan et al., 2016) have been identified. Some TFs, e.g., ANR1, LBD37/38/39, SPL9, NAC4, bZIP1, TGA1/TGA4, and HRS1, are nitrate-responsive while NLP6, NLP7, HNI9, TCP20, $N R G 2, B T 1 / B T 2$, and NLP8 are not. Among the key regulators, direct interactions of NLP6, NLP7, TGA1, bZIP1, TCP20, HRS1, and NLP8 with target gene promoters have been verified. Intriguingly, multiple transcriptional mechanisms are involved in nitrate responses. bZIP1, following a hit-and-run transcriptional model, transiently bind to its target gene promoters to enable a rapid and dynamic N-signal propagation (Para et al., 2014). The propagation of nitrate signaling into metabolism and stress response are observed in the clusters of genes potentially targeted by TGA1/TGA4 (Alvarez et al., 2014). The upregulation of gene expression of TGA1 is specifically dependent on a phospholipase
C (PLC)-calcium signaling pathway downstream of NRT1.1 (CHL1/NPF6.3) (Riveras et al., 2015). In response to nitrate, NLP7 was found to be retained in nucleus via a CPK-dependent phosphorylation to promote a genome-wide gene expression regulation, giving rise to the concept of primary nitrate signaling (Castaings et al., 2009; Marchive et al., 2013; Liu et al., 2017).

The primary nitrate signaling controlled by non-nitrateresponsive TFs that are not regulated by nitrate at the transcriptional level seems to regulate the proper level of expression of downstream nitrate-responsive TFs (Figure 2) (Marchive et al., 2013; Guan et al., 2014, 2017; Xu et al., 2016; Bellegarde et al., 2017; Liu et al., 2017). Moreover, several nonnitrate-responsive regulators, NLP6, NLP7, TCP20, NRG2, and $B T 1 / B T 2$ were shown to regulate the expression of the sentinel PNR genes, such as NRT1.1 (CHL1/NPF6.3), NRT2.1 and NIA1 at different nitrate concentrations (Guan et al., 2014, 2017; Araus et al., 2016; Xu et al., 2016). In contrast with NLP6, NLP7, and TCP20, the specific molecular function of NRG2 is not known; nevertheless, NRG2 could be also involved in primary nitrate signaling based on its regulatory roles in the PNR and their close ties to nitrate levels (Xu et al., 2016). It is well known that the protein-protein interactions define the specificity of signal transduction and transcriptional regulation (Lamb and McKnight, 1991; Pawson and Nash, 2000). The interaction between NLP7 and NRG2 was reported; however, its function in $\mathrm{N}$ signaling and regulation remains to be investigated (Xu et al., 2016). Most recently, a central regulatory nexus in response to nitrate availability, involving TCP20-NLP6/7 interactions, was identified (Guan et al., 2017). Centered on this regulatory nexus, a primitive transcriptional regulatory hierarchy is emerging (Figure 2) (Bellegarde et al., 2017; Guan et al., 2017; Liu et al., 2017).

TCP20 and NLP6/7 proteins are constitutively and ubiquitously expressed in plants (Winter et al., 2007; Castaings et al., 2009; Hervé et al., 2009; Danisman et al., 2012; Marchive et al., 2013; Chardin et al., 2014). TCP20 and NLP6/7 belong to two ancient gene families, the protein sequences of which contain multiple, deeply conserved motifs in plants (Cubas et al., 1999; Schauser et al., 2005; Martín-Trillo and Cubas, 2010). The NIN-like protein gene NLP7 was identified through its sequence similarity to the nitrate regulatory gene NIT2 in Chlamydomonas (Camargo et al., 2007; Castaings et al., 2009). NLPs and RWP-RK domain proteins, whose founding members are the nodulation-specific NIN proteins, constitute the RWP-RK family. The origin of NLPs predates the monocot/eudicot divide. The RWP-RK proteins are key regulators of $\mathrm{N}$ responses in plants (Schauser et al., 2005; Chardin et al., 2014). With their origin predating the emergence of land plants, TCPs are plant-specific TFs that function as the main regulators of plant morphology and architecture, mainly because of direct transcriptional control of cell cycle genes and regulation of hormone activity by class I TCPs, (Martín-Trillo and Cubas, 2010; Manassero et al., 2013; Nicolas and Cubas, 2016). Intriguingly, distinct but overlapping binding sites between the classes I and II TCPs indicate either coordinate or competitive regulation of transcription. For example, TCP20 and TCP9 (class I) and TCP4 (class II) were found to act antagonistically on jasmonic acid (JA) metabolism 


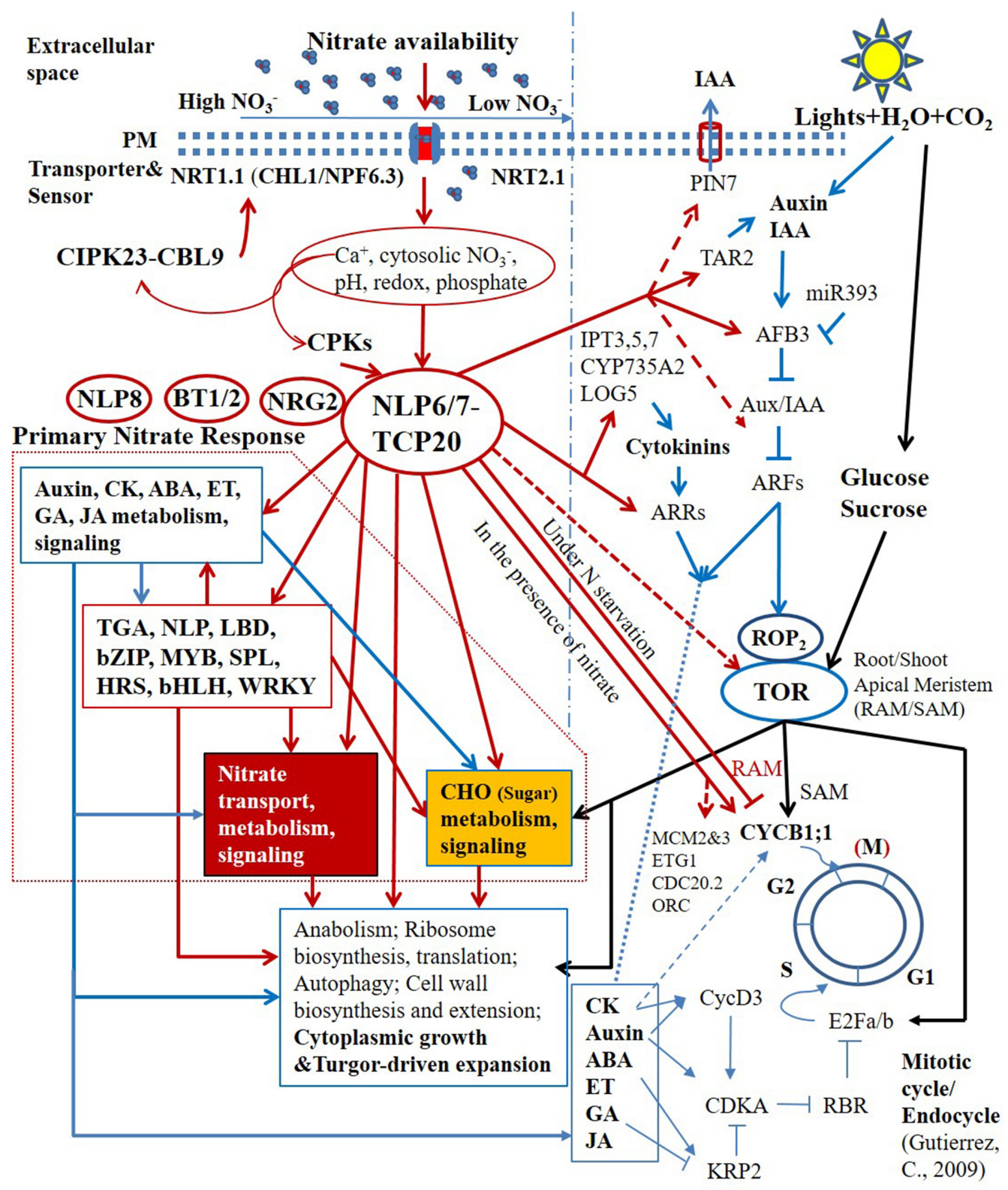

FIGURE 2 | Schematic representation of the central regulatory role of TCP20-NLP6/7 complexes in nitrate transcriptional hierarchy and nutrient-growth networks. Arrows and blunted lines represent positive and inhibitory regulations, respectively. Solid lines indicate defined pathways, whereas dashed lines indicate presumed or initially confirmed pathways.

and leaf development (Danisman et al., 2012). The delicate balance of transcriptional regulation between the two classes of TCPs in the distal meristem boundary zone where cell division transitions into expansion and differentiation was proposed as a key control of organ growth rate, ultimately shaping organs (Li et al., 2005). In inflorescence shoot apex, gibberellin (GA)regulated DELLA-TCP interactions control plant height (Daviere et al., 2014).

TCP20 and NLP6/NLP7 bind to adjacent sites in the upstream promoter region of the NR gene, NIA1, and physically interact under continuous nitrate and $\mathrm{N}$-starvation conditions. The subcellular localization and nuclear accumulation of single NLP6/7 and TCP20-NLP6/7 complexes depend on nitrate availability (Guan et al., 2017). The regulatory interactions could perceive nitrate availability via multiple upstream sensing and signal transduction in the cell membrane and cytosol, such as by the nitrate transceptor NRT1.1 (CHL1/NPF6.3), nitrate-CPK-NLP pathway (Liu et al., 2017). In the presence of nitrate, both NLP6 and NLP7 are retained in the nucleus. The nitrate-dependent nuclear retention in response to nitrate availability occurs within minutes. NLP6 and NLP7 thereby function as two partially redundant master regulators for 
rapid nitrate signaling and responses and growth (Marchive et al., 2013; Guan et al., 2017). The severe growth defects in nlp6 $n l p 7$ double mutants with nitrate as the sole $\mathrm{N}$ source, and in NR-null (nia1 nia2) mutants are comparable. Putative binding sites of NLP6 and NLP7 were found in the CYCB1;1 promoter region. The defective CYCB1;1 expression was also observed in $n l p 6 n l p 7$ double mutants, which, however, did not satisfy the significance test when total roots were measured, but would likely pass the test if measuring only root tips. Under $\mathrm{N}$ starvation, TCP20-NLP6/7 heterodimers accumulate in the nucleus. The transcriptional complexes not only bind to and upregulate sentinel nitrate-responsive genes for transport, assimilation and signaling, but also bind to and downregulate CYCB1;1, a division marker of apical meristems, for the control of G2/M transition in cell cycle progression, supporting root apical meristem (RAM) growth (Li et al., 2005; Guan et al., 2014, 2017). The direct molecular link between nitrate availability and G2/M cell cycle progression in the RAM is crucial for plant adaptive postembryonic development that depends on meristems. Genome-wide transcriptional profiling further revealed that potential NLP7 targeted genes include other cell cycle genes, such as MCM2/3, ETG1, CDC20.2, and ORC (Liu et al., 2017). Therefore, TCP20-NLP6/7 complexes have a much wider presence in cell cycle regulation (Figure 2).

\section{NITRATE, HORMONES, AND GLUCOSE-TOR IN ROOT APICAL MERISTEM GROWTH}

TCP20 regulates mitotic cyclin gene CYCB1;1 and putatively ribosomal protein genes by binding to the GCCCR motif in their promoters in vitro and in vivo, which was proposed to be a mechanism for regulation of the cell cycle and cell growth at a synchronized rate (Li et al., 2005; Guan et al., 2017). Under $\mathrm{N}$ starvation, total RNA, a majority of which is ribosomal RNA (rRNA), recorded in seedling roots of tcp20, $n l p 6, n l p 7, t c p 20$ $n l p 6, t c p 20 n l p 7$, or $n l p 6 n l p 7$ mutants was only approximately $50 \%$ percent of the total RNA recorded in seedling roots of $\mathrm{WT}$, when all were measured on same total fresh root weight, suggesting defective ribosome biogenesis and cell growth (Guan et al., 2017, unpublished results). It implies that these proteins may function as a complex in regulating ribosomal protein genes to stimulate ribosome biogenesis. The distinct nitrate-dependent TCP20-NLP6/7 interactions and their regulation under two conditions also support that nitrate signaling is an integral part of the synchronized the cell cycle and cell growth in meristem, likely via controlling cell division.

A master regulator of cytoplasmic growth is TARGET OF RAPAMYCIN (TOR), which is at the interface of growth and nutrient availability in unicellular organisms and through acquiring additional roles, becomes a central controller of organism growth, and energy and nutrient homeostasis in multicellular organisms (Zoncu et al., 2011; Sablowski and Dornelas, 2014). (m)TORC1 in both mammalian and yeast cells critically regulates and maintain the robust transcription of genes involved in ribosome biogenesis along with translation initiation and nutrient import under favorable growth conditions (Powers and Walter, 1999; Mayer et al., 2004; Xiao and Grove, 2009). That is in alignment with the roles of single NLP6 and NLP7 proteins in the presence of nitrate (Guan et al., 2017). TOR signaling is suppressed under stress conditions, leading to cell cycle arrest so as to prevent uncontrolled cell growth. However, in the face of constant nutrient stress in nature, the sustained cell growth in RAMs via transcriptionally repression of CYCB1;1 by TCP20-NLP6/7 complexes are crucial for plants as sessile organisms. It could enable continuous nutrient acquisition in soil and adequate remobilization within plants, which are key factors for survival by maximizing NUE (Masclaux-Daubresse et al., 2010). Intriguingly, sustained RAM growth was also physiologically observed under phosphate deficiency, which is at the expense of photosynthesis (Kang et al., 2014). Moreover, during cell expansion that predominates in post-mitotic cells, the TCP20-NLP6/7 also play critical regulatory roles in cell wall biogenesis and modification (Hervé et al., 2009; Danisman et al., 2012; Karve et al., 2016). The growth of organs and whole plants depends on system-wide synchronized coordination of nutrient availability, cell growth and cell-cycle progression, for which the functions of TCP20-NLP6/7 interactions are central.

Interestingly, the TCP20-NLP6/7 regulatory nexus employs the type I/II Phox and Bemlp (PB1) domains of NLP6/7, a protein-interaction module conserved in animals, fungi, amoebas, and plants (Sumimoto et al., 2007; Chardin et al., 2014; Guan et al., 2017). In animals, PB1 domains are employed for activation of mTOR1 by amino acids and organizing growth factors (Linares et al., 2015). In plants, the type I/II PB1 domains are also employed in the homo- and hetero-oligomerization of auxin response factor (ARF) TFs and auxin/indole 3acetic acid (Aux/IAA) repressor proteins (Boer et al., 2014; Korasick et al., 2014; Guilfoyle, 2015). This indicates that the TCP20-NLP6/7 interactions are part of a more general pattern used for nutrient-growth signaling, cellular homeostasis, and morphogenetic signaling in both plants and animals (Guan et al., 2017). However, TCP20-NLP6/7 regulatory nexus compares with recently discovered plant glucose-TOR signaling in that both of them are not well framed in conventional non-transcriptional mechanisms of mammalian TOR, which indirectly modulate limited messenger RNAs and target genes via 4E-BP1 and S6K1 phosphorylation (Xiong et al., 2013; Guan et al., 2017). Instead, they are two central transcriptional machineries controlling a broad range of nutrient-growth gene expression at the wholeplant level (Xiong et al., 2013; Guan et al., 2017).

For plant growth and development, nitrate, sugars, and the phytohormones, particularly auxin and CKs, are of vital importance. They are integral parts of the regulation of the dynamic balances of cell division and cell differentiation, which controls organ shape and size. Especially in root growth, they are intricately coordinated in controlling the balance between the cell cycle and cell growth (Xiong et al., 2013; Sablowski and Dornelas, 2014; Barrada et al., 2015; Guan et al., 2017). CK and auxin have long been implicated in regulating the components of the cell cycle (Himanen et al., 2002; Perrot-Rechenmann, 2010; Schaller et al., 2014). In Arabidopsis, RAM growth is under the antagonistic effects of auxin and $\mathrm{CK}$, which mediate cell division 
at the apical meristem and cell differentiation at the transition zone, respectively (Ioio et al., 2007). For LR formation consisting of pericycle activation and meristem establishment, auxin is a dominant regulator (Himanen et al., 2002; Fukaki and Tasaka, 2009). CK was also reported to repress LR initiation and promote LR elongation (Rani Debi et al., 2005; Laplaze et al., 2007). Recently, the glucose-TOR signaling pathway was reported to control the G1/S transition by an unconventional mechanism of transcriptional regulation. TOR kinase directly phosphorylates and activates $\mathrm{E} 2 \mathrm{Fa}$, which in turn transcriptionally activates S-phase genes in response to glucose and sucrose signaling, which is independent of S6K, RBR or translational control (Xiong et al., 2013). The glucose-TOR signaling for the glycolysismitochondrial energy relays is indispensable for RAM growth.

Intriguingly, the induction level of primary auxin and CK marker genes and spatial expression of patterning genes were intact in the presence of rapamycin or antimycin A (AMA) in WT (in both cases TOR activity is inhibited) and in tor seedlings. Upon glucose starvation, neither RAM cell number nor RAM length were significantly reduced, which is overtly opposite to what was observed in RAM upon $\mathrm{N}$ starvation, where arrest at the G2/M transition occurred (Xiong et al., 2013; Guan et al., 2017). Under N starvation, significant reductions of LR number per plant were displayed across the mutant lines, $n l p 6, n l p 7$, tcp20 nlp6, tcp20 nlp7, and nlp6 nlp7 (Guan et al., 2017, unpublished results). It is consistent with that in Arabidopsis, the initial xylem pole pericycle cell divisions during first LR initiation event are accompanied with regulation of G2/M transition (Himanen et al., 2004; Malamy, 2005). Auxin and CK signaling and stem cell niche maintenance seems not to rely on sugar signaling and metabolism pathways (Xiong et al., 2013). The accumulating evidence as reviewed here suggests that nitrate signaling and metabolism is crucial for hormone signaling and maintenance of stem cell niche integrity.

TORC1 and TORC2 complexes, and a large part of the evolutionary "core" of TOR pathway likely originated in or before the last eukaryotic common ancestor (LECA) that gave rise to all currently known living eukaryotic species (van Dam et al., 2011). Although the two TOR complexes are found in other major lineages of eukaryotes, plants possess only TORC1 (van Dam et al., 2011). In plant TOR signaling as has been uncovered so far, the integration of $\mathrm{N}$ status with cell growth and the cell cycle, which is the main component in TOR1 pathways of both yeast and mammals and required by virtually all eukaryotic cells, is still missing. It is mainly because the upstream regulators that directly sense $\mathrm{N}$ availability and organize growth factors are unknown. Plants lack orthologs of small guanosine 59-triphosphatases (GTPases): Ras homolog enriched in brain (RHEB), and Rag guanosine 59-triphosphatases (RAGs) (Xiong and Sheen, 2014). TOR signaling is highly conserved; however, it is adequately flexible to include new signals and mechanisms in response to environmental challenges in the evolution of animals and plants (van Dam et al., 2011). For example, insulin signaling is an animal-specific addition to the pathway to use sugar (glucose) for cellular growth in a multicellular environment. Recently, the plant-specific small GTPase Rho-related protein 2
(ROP2) (Li et al., 2001) was demonstrated to transduce lightauxin signal to activate TOR by direct interaction (Li et al., 2017). Interestingly, TOR kinase can also be activated by nitrate and amino acids via S6K1 T449 phosphorylation by unknown mechanisms in Arabidopsis seedlings (Xiong and Sheen, 2015). Could TCP20-NLP6/7 complexes function in parallel with plant TOR or upstream of plant TOR for N signaling?

The glucose-TOR signaling imposes an overall limit on plant organ growth, specifically on organ size (Sablowski and Dornelas, 2014). By contrast, nitrate and its close interplay with hormones have a determining effect on patterning tissues and shaping organs (Crawford, 1995; Stitt, 1999; Forde, 2002; Miller et al., 2008; Ruffel et al., 2011; Nacry et al., 2013; Guan et al., 2014, 2017; Mounier et al., 2014; Sablowski and Dornelas, 2014; Krouk, 2016; Ristova et al., 2016). This is a strong indication of interaction and integration of nitrate and hormonal signaling pathways in plant growth and development. One thing is clear: RAM growth that takes place underground is particularly under convergent regulation of nitrate and hormone signaling. Notably, the distinct mechanism and coordination between hormone and glucose-TOR energy signaling are involved in regulation of shoot apical meristem (SAM). Light, a main aboveground environmental cue, is required for producing auxin, which in turn can activate downstream ROP2-TOR-E2Fa/b signaling pathway and promoting SAM growth (Li et al., 2017). The involvement of nitrate signaling in SAM growth should also be investigated in the integrated context.

\section{NITRATE IN AUXIN BIOSYNTHESIS, TRANSPORT, SIGNALING, AND RESPONSES}

Auxins are a class of essential phytohormones involved in tailoring plant growth and morphology to environmental conditions (Vanneste and Friml, 2009; Overvoorde et al., 2010). As the main endogenous auxin in most plants, indole-3acetic acid (IAA) is the most potent native auxin, regulating almost every aspect of plant life, i.e., growth, development, and biotic and abiotic stress responses (Woodward and Bartel, 2005; Zhao, 2012). IAA biosynthesis is defined by a two-step complete pathway where indole-3-pyruvate (IPA) is converted from tryptophan (Trp) by the TAA family of amino transferases, before IPA being converted to IAA by the YUC family of flavin monooxygenases (Zhao, 2012). It is generally accepted that auxin regulation of plant morphogenesis relies on its tissue-specific concentration gradients collectively formed by the processes of auxin biosynthesis, conjugation, degradation and transport (Normanly, 2010). Recent studies also showed that localized auxin biosynthesis is indispensable in many developmental processes including embryogenesis, seedling growth, root development, vascular patterning, phyllotaxis and flower development (Cheng et al., 2006, 2007; Overvoorde et al., 2010; Pinon et al., 2013; Chen et al., 2014). In Arabidopsis roots, defective localized auxin biosynthesis cannot be replenished by auxin transported from shoots, indicating that shoot-derived 
auxin alone is not sufficient for supporting root elongation and root gravitropic responses (Chen et al., 2014).

Notably, N availability directly regulates TAA1 and its close homologs TAR1 and TAR2 in the first step of IAA biosynthesis (Ma et al., 2014). In Arabidopsis, the expression levels of the three genes in roots and shoots under high $\mathrm{N}$ conditions $(3 \mathrm{mM}$ $\mathrm{NH}_{4} \mathrm{NO}_{3}$ ) were compared with those under low $\mathrm{N}$ conditions $\left(0.1 \mathrm{mM} \mathrm{NH} \mathrm{NO}_{3}\right)$ after 7 days treatment (Ma et al., 2014). The expression of TAR2 was significantly induced by low $\mathrm{N}$ in roots, where the expression of TAA1 was moderately induced. The expression of TAA1 and TAR1 were both repressed in shoots. TAR2 was expressed in the root pericycle and vasculature of root maturation zone near the root tip. The tar2 mutants showed repressed auxin accumulation in LR primordia and reduced LR primordia emergence and numbers under low $\mathrm{N}$ conditions (Ma et al., 2014).

However, with ammonium in the media, it was difficult to identify which $\mathrm{N}$ source, nitrate or ammonium, or both of them, could be responsible for the gene expression regulation. The recent genome-wide transcriptional profiling showed that TAR2 and PIN-FORMED PROTEIN 7 (PIN7) are among the top NLP7activated genes, together with nitrate assimilation genes such as NiR, NIA1, FNR2, and NRT2.1 (Marchive et al., 2013; O'Malley et al., 2016; Liu et al., 2017). Plasma membrane-localized PIN7 is a main auxin efflux carrier protein (Friml et al., 2003). This evidence substantiates that the auxin biosynthesis and transport is transcriptionally regulated by nitrate in roots. It further suggests that the TCP20-NLP6/7 complexes function upstream of auxin-ROP2-TOR-E2Fa/b signaling pathway (Figure 2).

Auxin transport has been postulated to be a major factor determining intercellular and intracellular distributions of IAA. In plant cells, transporters and their asymmetrical localization are required for suggested directional efflux of anionic auxins and formation of polar flow. Therefore, NLP7-regulated auxin efflux via PIN7 could contribute to regional auxin gradient and local maxima to establish and maintain a root primordium and determine LR numbers (Overvoorde et al., 2010). Auxin was also shown to be transported away from the LR primordium by NRT1.1 (CHL1/NPF6.3) at low nitrate conditions $(<0.5 \mathrm{mM})$, therefore preventing the growth of pre-emerged LR primordia and young LRs; when nitrate being plentifully supplied, auxin accumulated in the LR primordium to promote growth as a result of repressed auxin transport activities of NRT1.1 (CHL1/NPF6.3) (Krouk et al., 2010b; Mounier et al., 2014). The phosphorylated form of NRT1.1 (CHL1/NPF6.3) is predominantly active in auxin transport among the point mutations in NRT1.1 (CHL1/NPF6.3) being tested for auxin influx activity in Xenopus oocytes. It is also responsible for modulation of auxin gradient in LR primordium (Bouguyon et al., 2015).

Transport of other plant hormones across plasma membranes also requires transporter proteins that are spatiotemporally regulated during development instead of occurring simply by diffusion (Saito et al., 2015). Interestingly, more new substrates, such as ABA, GAs, jasmonoyl-L-isoleucine, and glucosinolates, were recently found to be transported by NRT1/PTRs or NPFs (Kanno et al., 2012; Nour-Eldin et al., 2012; von Wittgenstein et al., 2014; Saito et al., 2015; Chiba et al., 2015; Tal et al.,
2016). In addition to being nitrate transporters, the capability of transporting hormones was suggested to be another critical feature of this family in plants. However, no long-distance transport of any hormones, i.e., loading/unloading of them into/out of xylem/phloem vessels, has been demonstrated. All the NRTs-dependent transports so far reported only involve local redistribution of the hormones (Kanno et al., 2012; Tal et al., 2016).

In Arabidopsis roots, a miR393/AFB3 regulatory module was identified as nitrate-responsive, which integrates nitrate and auxin signaling in modulating both primary and LR growth (Vidal et al., 2010). miR393 was the only N-responding sRNA identified in 454 sequencing and it specifically responded to nitrate not sucrose. The auxin receptor genes, TIR1, AFB1, $A F B 2$, and $A F B 3$, are regulated by miR393. Among them, a strong induction of $A F B 3$, also the only induction, by nitrate, was observed. The AFB3 induction peaked at $1 \mathrm{~h}$ after nitrate $\left(5 \mathrm{mM} \mathrm{KNO}_{3}\right.$ ) exposure, and the nitrate induction of miR393 peaked at $2 \mathrm{~h}$, strikingly coinciding with the fast declining of the already peaked expression of AFB3. This miR393-dependent repression was not observed in NR-null mutants, correlating with the absence of miR393 expression. Further evidence support that nitrate signal alone is responsible for the transcriptional induction of $A F B 3$ in root tips, which can be subsequently posttranscriptionally repressed by miR393 induced by unidentified $\mathrm{N}$ metabolite(s) downstream of nitrate reduction. Such a mechanism agrees with the type I incoherent feed-forward loop (FFL) motif featured in transcriptional controls in yeast, bacteria, and mammals (Shen-Orr et al., 2002; Mangan and Alon, 2003; Tsang et al., 2007; Vidal et al., 2010). Accompanied with it, accumulation of auxin and the regulatory of many auxinresponsive and auxin-related genes involved in multi-level of auxin signaling and responses in the root tips and pericycle cells were also observed. The nitrate-regulated miR393/AFB3 module is capable to integrate nitrate $(5 \mathrm{mM})$ signal into auxindependent root growth. Shorter primary root due to inhibited root elongation and more dense LRs due to higher rate of LR initiation and emergence were formed in response to nitrate availability in soil (Vidal et al., 2010).

Auxin binds to TIR1/AFB receptors, members of the $S_{C F} F^{T I R 1 / A F B}$ E3 ubiquitin ligase complex. It promotes the recognition and degradation of the Aux/IAA repressors via by polyubiquitination, which free the inhibition of the auxin response factors (ARFs) that allows auxin-responsive transcription (Chapman and Estelle, 2009). The activation of $A F B 3$ is not the cause but one of the consequences of nitrate response (Vidal et al., 2013). AFB3-dependent auxin signaling, including perception and response, and its regulation of root growth is downstream of nitrate signaling in response to nitrate availability, independent of nitrate transport and metabolism. Specifically, NAM/ATAF/CUC TF, NAC4 and its targeted TF gene $O B P 4$, functions as a downstream branch of nitrate-AFB3. The nitrate-AFB3-NAC4-OBP4 signaling, with all their proteins found expressed in root pericycle cells, is required for nitratedependent LR initiation and emergence. The NAC4-OBP4 part of the pathway is possibly regulated by AUX/IAA proteins, such as IAA14. These observations suggest convergent regulation 
between nitrate and auxin signaling pathways on LR growth (Vidal et al., 2013).

With three different NRT1.1 (CHL1/NPF6.3) mutants: chl1-5, chl1-9, and NRT1.1 ${ }^{\text {T101D }}$ mutants, the role of nitrate membrane sensor/transporter, NRT1.1 (CHL1/NPF6.3) in regulating nitrate response of AFB3 and NAC4 were tested (Vidal et al., 2014a). Specifically, chl1-5 is a deletion mutant without uptake and sensing function; chl1-9 is defective in both high- and low-affinity nitrate uptake but not in nitrate signaling, and NRT1.1 ${ }^{\text {T101D }}$ mutant mimics a constitutively phosphorylated transporter, with only the high-affinity mode (Ho et al., 2009). Interestingly, not like sentinel PNR genes, such as NRT2.1, NIA1, and NIA2, which were tightly controlled by the signaling functions of NRT1.1 (CHL1/NPF6.3), only the transport function of the NRT1.1 (CHL1/NPF6.3), not those of NRT2.1, NRT1.2 (NPF4.6/AIT1), and NRT2.2, matters on the expression levels of $A F B 3$ and NAC4. Moreover, the nitrate induction of $A F B 3$ and NAC4 was independent of affinity mode of NRT1.1 (CHL1/NPF6.3). Notably, the NRT1.1 ${ }^{\text {T101D }}$ was demonstrated to modulate auxin gradient in LRP as WT NRT1.1 (CHL1/NPF6.3) in the absence of nitrate, which excludes the possible involvement of auxin transport of NRT1.1 (CHL1/NPF6.3) in the nitrate induction of $A F B 3$ and NAC4 (under $5 \mathrm{mM}$ nitrate treatment). It was suggested that an unidentified signaling pathway independent from the signaling via NRT1.1 (CHL1/NPF6.3) phosphorylation was triggered by NRT1.1 (CHL1/NPF6.3) transport of nitrate (Vidal et al., 2014a). It further substantiates that nitrate responses, which include the nitrate-AFB3-NAC4-OBP4 auxin perception, signaling and response, are established via multiple signaling mechanisms and their coordination (Liu et al., 2017).

\section{NITRATE IN CYTOKININ BIOSYNTHESIS, SIGNALING, AND RESPONSES}

Involved in many phases of plant growth and development, cytokinins (CKs) are a class of phytohormones known for promoting cell division and differentiation (Mok and Mok, 2001). CKs can interact with auxins either synergistically or antagonistically and also promote the production of ethylene (Mok and Mok, 2001). Since CKs are translocated at cellular and whole-plant levels, CK root-shoot communication is proposed as a model of systemic signaling for nutrient status (Sakakibara, 2006; Ruffel et al., 2011). CK activity in plants is tightly related to nitrate availability. Nitrate, not its downstream $\mathrm{N}$ metabolites, has been known to induce rapid de novo $\mathrm{CK}$ synthesis and accumulation in the roots of barley, maize, and Arabidopsis (Takei et al., 2004). CK biosynthesis can also occur in other tissues where the adenosine phosphate-isopentenyltransferases (IPTs) are expressed. IPTs are key enzymes that catalyze the first and ratelimiting step of $\mathrm{CK}$ biosynthesis, i.e., prenylation of adenosine $5^{\prime}$ phosphates, such as ATP and ADP, at the $\mathrm{N}^{6}$-terminus with dimethylallyl diphosphate (DMAPP) (Sakakibara, 2005). IPT expression is ubiquitous and peaks in proliferating tissues. In Arabidopsis, IPT3 is regulated by $\mathrm{N}$ in a nitrate-specific manner. The expression of IPT3 and several Arabidopsis response regulators $3,5,6(A R R 3,5,6)$, is induced by nitrate during the
PNR (Wang et al., 2004). IPT3 was strongly induced in roots and weakly induced in shoots in both WT and NR-null mutant plants during the PNR, partly mediated by NRT1.1 (CHL1/NPF6.3) (Wang et al., 2004, 2009). When nitrate $\left(10 \mathrm{mM} \mathrm{KNO}_{3}\right)$ was re-supplied to nitrogen-limited seedlings, the kinetics of IPT3 and NIA1 transcripts that were rapidly accumulated within $1 \mathrm{~h}$. resembled each other (Takei et al., 2004). NIA1 is among the most induced genes in the PNR (Wang et al., 2000); therefore, nitrate has a tight control over CK biosynthesis via activation of IPT3. All are consistent with the idea that IPT3 is the main determinant of short-term nitrate-dependent CK biosynthesis, particularly in roots, in response to the rapid change of nitrate availability in soil (Takei et al., 2004). More recent transcript profiling of CK metabolism and signaling genes further revealed that besides IPT3, high nitrate upregulates the transcripts of CYP735A2, which is responsible for the production of trans-zeatin-type ( $t \mathrm{Z}$ type) CK in roots, while it downregulates that of LOG5. The typeA ARR genes ARR3, ARR5, and ARR7, like the CK metabolism genes, were shown to respond to nitrate but not to ammonium (Ramireddy et al., 2014; Liu et al., 2017). Also induced by nitrate are CYTOKININ RESPONSE FACTORS (CRFs) (Rashotte et al., 2006; Liu et al., 2017), which is known to be transcriptionally induced by $\mathrm{CK}$ and whose disruption affects the basal expression of a significant number of CK-regulated genes, including the type-A ARRs. CRFs are implicated in promoting root and shoot growth and leaf senescence (Raines et al., 2016).

Among the most highly expressed IPTs, IPT3 is mainly expressed in phloem tissue throughout the whole plant, specifically found in phloem companion cells, and IPT5 is in the LR primordium and pericycle, which are consistent with where CK biosynthesis is suggested to occur. The spatial differentiation of IPTs transcript also suggests that in terms of CK production, IPT5 and IPT3 could contribute most in roots, while IPT3 is most dominant in shoots. IPT5 was not responsive to either nitrate or ammonium under a short-term hour-long treatment, however, was demonstrated to be a "long-term" or systemic N statusresponsive gene, with its transcript abundance being responsive to both nitrate and ammonium media at different concentrations over a long course of observation, 11 days. By contrast, IPT3 expression pattern (strongly in roots and weakly in shoots) is quickly induced during the PNR, a frequently occurring wholeplant nitrate response due to dramatic fluctuations of nitrate in soil (Wang et al., 2004). The close regulation of CYP735A2 and IPT 3 by nitrate could be a major factor shaping nitrate-dependent spatiotemporal CK distribution in plants and regulating root system architecture in response to a variety of abiotic stresses (Ramireddy et al., 2014).

Compared to the rapid nitrate response of IPT3 (within $1 \mathrm{~h}$ ), CK signaling has a relatively delayed (within $4 \mathrm{~h}$ ) feedback control over most the IPTs, IPT1,3,5,7 by downregulating them in roots, where IPT5 and IPT7 can be upregulated concurrently by auxin (Miyawaki et al., 2004). IPT7 is expressed in root stele and phloem companion cells. To add another layer of dynamic complexity of interactions, CK and auxin also exert feedback controls over nitrate uptake and assimilation (Guo et al., 2002; Krouk, 2016). In this context, nitrate and two hormonal mediators, $\mathrm{CK}$ and its antagonistic partner, auxin, act 
in concert to modulate CK biosynthesis in root development. The dual nitrate-CK response system, employing IPT3 and IPT5, along with CK/auxin feedback regulations on IPTs could have a critical role in mediating root foraging for nitrate, a classic plant response to nitrate availability. To compete for nutrients in diverse soil microenvironments, plants have evolved the unique capability to proliferate LRs preferentially in nutrient-rich zones, called "root foraging" (Drew et al., 1973). Root foraging for nitrate involves both local and systemic signaling (Ruffel et al., 2011; Guan et al., 2014; Mounier et al., 2014). Besides their effects on localized CK and auxin biosynthesis, the concerted nitrate-CK-auxin regulation could also be an integral part of $\mathrm{N}$ systemic signaling that coordinates nutritional requirements among different organs and at different developmental stages. Notably, ammonium and downstream $\mathrm{N}$ metabolites are unlikely to be major players in systemic $\mathrm{N}$ signaling (Howitt and Udvardi, 1999; Forde, 2002; Bellegarde et al., 2017).

Using WT, NR-null and ipt3,5,7 mutants in split-root experiments, nitrate signaling was demonstrated to act both locally and systemically to integrate $\mathrm{N}$ supply and demand. The systemic $\mathrm{N}$ signaling also involves a nitrate-CK relay, where IPT3, IPT5 and IPT7 play a central role. The nitrate-CK relay is suggested to be necessary for shaping root foraging (Ruffel et al., 2011). The study also suggested that there is an additional systemic signaling pathway also required. Using decapitation experiments, the concept of shoot-root CK-dependent feedback specifically for $\mathrm{N}$ demand was proposed. However, questions remain. Is decapitation a definitive way to confirm CK's independence from nitrate in the systemic $\mathrm{N}$ demand signaling? In analogy to CK's root-shoot-root signaling/relay mechanism, a similar model was proposed for small peptides in root foraging (Okamoto et al., 2013; Tabata et al., 2014; Ohkubo et al., 2017). Clavata3/ESR (CLE)-related peptide signal and $\mathrm{N}$ starvationtriggered C-terminally Encoded Peptide (CEP) were identified as "satiety" and "hunger" signals. In root-to-shoot route, CLE and CEP were first derived from roots, then transmitted to shoots where being perceived by leucine-rich repeat receptor-like kinase (LRR-RLK) receptors HAR1 and CEPRs, respectively. In the following shoot-to-root route, CEP Downstream1 (CEPD1) and CEPD2, two phloem-specific polypeptides, are regulated by CEPRs and then transmitted to roots, where NRT2.1 is thereby activated (Ohkubo et al., 2017). Notably, the two hormonedependent systemic signaling pathways could be necessary but not sufficient for root foraging independent of local and systemic signaling by nitrate (Ruffel et al., 2011, 2016; Guan et al., 2014; Mounier et al., 2014).

Furthermore, there is also intriguing spatiotemporal regulation of CK signaling by nitrate in the context of root foraging. The expression of primary CK-response genes and negative regulators of CK signaling, type-A ARRs(3,5-9) was globally up-regulated by nitrate in roots and shoots at a later time ( $2 \mathrm{~h}, 8 \mathrm{~h}$, and 2 days) compared with the much quicker expression of IPT (within $1 \mathrm{~h}$ ) (Ruffel et al., 2011). The response levels of ARRs in NR-null roots and shoots are very comparable, in some cases even lower in roots, which is strikingly opposite to those of IPTs (Wang et al., 2004). Since both CK biosynthesis after IPT induction and induction of ARRs by the produced CK are rapid (Wang et al., 2002), the much later $(>8 \mathrm{~h}$ ) regulations of ARRs by nitrate (Ruffel et al., 2011) suggest additional nitrateregulated mechanism(s) are likely to be involved rather than CK biosynthesis-dependent replay.

Another branch of the evidence that deserves our attention is that TCP20 as a cell-autonomous systemic nitrate regulator is clearly required for the nitrate foraging by roots (Guan et al., 2014). tcp20 mutants strongly suppress the preferential growth of LRs by equalizing growth across heterogeneous nitrate environments, mainly through increasing the LR growth on lownitrate media of split-root plates as if the plants were impervious to any systemic signal. An earlier study showed that the main class of AtTCP20::EAR-repressed genes include ARR4,6,7 and AUX/IAA13,16,27 that repress ARFs in auxin signaling (Hervé et al., 2009). All the genes possess at least one class I TCP binding motif in their promoters. In $t c p 20$ mutants, the foragingdefective LR growth in high/low nitrate media was largely due to much shorter/longer LR length but not to the less/more number of LRs (Guan et al., 2014). The RAM growth is indeed under the balanced control of nitrate-CK-auxin signaling as also previously discussed. The concerted nitrate-CK-auxin signaling could also have TCP20 as a mediator between CK and auxin for the regulation of root foraging.

\section{NITRATE IN ABSCISIC ACID DECONJUGATION, DEGRADATION, TRANSPORT, AND SIGNALING}

Nitrate sensing, signaling and regulation, and their interaction with hormones are very dose-dependent. Beyond the optimal range (1-10 $\mathrm{mM}$ ) corresponding to steady-state cytosolic nitrate concentrations (4-6 mM) (Miller and Smith, 2008), additional interaction between nitrate and hormones occurs. Transferring Arabidopsis seedlings between media with different nitrate concentrations has been used to mimic plant responses to a variety of nitrate availability in soil. The reversible oscillating responses have been thereby observed in nitrate-dependent hormone biosynthesis and accumulation, and LR growth (De Smet et al., 2003; Tian et al., 2009).

Abscisic acid has been long regarded as a stress hormone crucial to plant abiotic and biotic stress responses ( $\mathrm{Zhu}, 2002$; Kiba et al., 2012). In the face of high nitrate concentrations (approximately $>10 \mathrm{mM}$ ), nitrate and $\mathrm{ABA}$ are close partners, especially in the control of LR growth (Signora et al., 2001; De Smet et al., 2003). Nitrate serves as an osmolyte; therefore, the changes of nitrate availability and concentration alter osmotic potential of plant cells. Repression of LRs in Arabidopsis due to very high nitrate $(30 \mathrm{mM})$ resembled the repressed growth of LR treated by $30 \mathrm{mM} \mathrm{KCl}$ or $60 \mathrm{mM}$ mannitol. All the treatments, including high nitrate $(>30 \mathrm{mM})$, could impose osmotic stress (Deak and Malamy, 2005). Exogenous ABA also inhibits LR development, mimicking high nitrate repression of LR (De Smet et al., 2003). Furthermore, ABA synthesis and ABA-sensing mutants displayed significantly reduced inhibitory effects by high nitrate concentrations ( $>10 \mathrm{mM}$ ) (Signora et al., 2001). The ABA-induced growth arrest occurred right after LR 
emergence and before the activation of the LR meristem, which is due to ABA suppression of the transcription of two cell cyclerelated genes, $C Y C D 3 ; 1$ and $C D K B 1 ; 1$. It serves as a checkpoint that, however, is reversible (De Smet et al., 2003).

The accumulation of ABA was detected mainly in the endodermis and quiescent center of Arabidopsis root tips, similar to the expression pattern of SCARECROW, and to a lesser extent in the vascular cylinder (Ondzighi-Assoume et al., 2016). A threefold increase of ABA level in root tips was observed in seedlings being transferred from the medium containing $20 \mathrm{mM}$ nitrate to that containing $30 \mathrm{mM}$ nitrate. It was accompanied by the increased activity of the endoplasmic reticulum-localized, ABA-GE-deconjugating enzyme $\beta$-GLUCOSIDASE1, but not with de novo ABA biosynthesis. High nitrate thereby stimulates release of bioactive $\mathrm{ABA}$ from the inactive storage form, $\mathrm{ABA}$ glucose ester (ABA-GE) (Ondzighi-Assoume et al., 2016). In parallel with this, osmotic stress causes accumulation of the endogenous $\mathrm{ABA}$; therefore, $\mathrm{ABA}$ has been regarded as a mediator of responses of osmotic stress imposed by drought and high salt (Zhu, 2002). All suggests that both ABA and high nitrate share a single pathway which is likely part of general osmotic stress responses, during a specific LR development stage in Arabidopsis. And notably the high nitrate-ABA pathway is independent of auxin (De Smet et al., 2003).

ABA-IMPORTING TRANSPORTER (AIT) 1, also characterized as the constitutive, low-affinity nitrate transporter NRT1.2 (NPF4.6), mediates cellular ABA uptakes during seed germination and post-germination growth of Arabidopsis (Kanno et al., 2012). In response to drought stress, plants synthesize ABA to trigger closing of stomatal pores. NRT1.2 (NPF4.6/AIT1) is suggested to be involved in regulation of stomatal aperture in inflorescence stems via transporting ABA synthesized in vascular tissues to guard cells. Being an osmolyte, nitrate is also known for controlling gas exchange by stomates. In the presence of nitrate, NRT1.1 (CHL1/NPF6.3) is required in nitrate induced depolarization and nitrate accumulation in guard cells during stomatal opening. Its mutants showed reduced stomatal opening and transpiration rates in the light or when deprived of $\mathrm{CO}_{2}$ in the dark, leading to drought resistance (Guo et al., 2003). The two nitrate transporters seem to be able to work in a "coordinated" manner to regulate the stomatal functions in response to drought stress or nitrate, whichever signal becomes dominant. An intriguing coordination between the two transporters occurred when the induction of NRT1.1 (CHL1/NPF6.3) by nitrate caused a transient repression of NRT1.2 (NPF4.6/AIT1) (Huang et al., 1999). With the exception of this temporary coupled reaction of NRT1.1 (CHL1/NPF6.3) and NRT1.2 (NPF4.6/AIT1) in response to nitrate induction, NRT1.2 (NPF4.6/AIT1) is constitutively expressed before and after nitrate exposure (Huang et al., 1999).

The mechanism of interaction between nitrate and ABA signaling, which could be behind such coordination is further understood in roots. In another study, ABA insensitive2 (ABI2; an ABA inactivated PP2C) has been identified as a potential interacting protein of the CBL1-CIPK23 complex, which like CBL9-CIPK23 has inhibitory effects on nitrate transport of NRT1.1 (CHL1/NPF6.3), under $>30 \mathrm{mM}$ nitrate (Leran et al., 2015). The CBL9-CIPK23 complex is known to be responsible for the phosphorylation of the NRT1.1 (CHL1/NPF6.3), resulting in switching to high-affinity transport mode in response to low nitrate availability ( $<1 \mathrm{mM}$ ) (Ho et al., 2009). ABI2 negatively regulates the full activation of CBL1-CIPK23 toward their targeted proteins by substantially reducing CIPK autophosphorylation and CIPK-dependent phosphorylation of the $\mathrm{Ca}^{2+}$-sensor moiety in the associated CBL (Hashimoto et al., 2012). During drought and osmotic stresses, stress-induced ABA could inactivate ABI2 by RCAR/PYL/PYR interaction, which enhances phosphorylation of NRT1.1 (CHL1/NPF6.3) and phosphorylation of AKT1 by CBL1-CIPK23. The similar phenotypes associated with nitrate transport and signaling were observed in both chll and abi2-2 mutants. The mechanism could allow plants to rechannel their energy and resource from nitrate assimilation to stress response via reducing nitrate uptake in favor of uptake of potassium ions, which is critical in abiotic and biotic stress responses (Wang et al., 2013). It suggests that ABA-dependent stress signals could be required to be conveyed to and processed through the nitrate transceptor, NRT1.1 (CHL1/NPF6.3), so that the abiotic stress response is likely a collective decision made in conjunction with nitrate signaling. The conclusion is also supported by the results of an earlier study that in Arabidopsis guard cells, ABI1 and ABI2 protein phosphatases are downstream of NR-mediated nitric oxide (NO) in the ABA signal-transduction cascade (Desikan et al., 2002). The NO synthesis regulated by nitrate signaling is required for ABA-induced stomatal closure (Desikan et al., 2002).

Recently, a direct molecular link between nitrate signaling and $\mathrm{ABA}$ degradation in seed germination was revealed (Yan et al., 2016). The conserved nitrate regulator, NLP8, was found to regulate $\mathrm{ABA}$ catabolism and activate the expression of CYP707A2, which is indispensable for nitrate-induced seed germination. This activation appears to occur directly, through NLP8 binding to the promoter of CYP707A2, which encodes ABA 8' -hydroxylase, a key ABA catabolic enzyme (Kushiro et al., 2004; Yan et al., 2016). ABA negatively regulates the germination process. Hence, seed germination after the onset of imbibition can be triggered in a timely fashion upon reduced level of ABA. Notably, CYP707A2 has been shown to be a hub processing environmental signaling, i.e., nitrate, light, and temperature, during germination (Footitt et al., 2011, 2013).

\section{NITRATE IN ETHYLENE BIOSYNTHESIS AND SIGNALING}

With the chemically simplest form among phytohormones, ethylene is a gaseous signal molecule and potent regulator of developmental adaptations (Ecker, 1995; Bleecker and Kende, 2000). The production of ethylene is regulated by internal signals during developmental phases, including seed germination, root growth, fruit ripening, organ senescence, etc., and also in response to biotic and abiotic stresses (Wang et al., 2002). Compared with the significant ABA accumulation in roots of the seedlings that were transferred from low nitrate $(20 \mathrm{mM})$ to high nitrate $(30 \mathrm{mM})$, transferring seedlings from low nitrate $(0.1 \mathrm{mM})$ to high nitrate $(10 \mathrm{mM})$ caused a rapid 
burst of ethylene production in roots (Tian et al., 2009). Both of them contribute to the inhibitory effects of LR growth exerted by transferring to high nitrate conditions. Strikingly, the LR growth inhibition and the elicited ethylene evolution can be reversed by transferring the seedlings back to the low nitrate $(0.1 \mathrm{mM})$, similar to the reversible arrest observed in the case of ABA (De Smet et al., 2003). Ethylene is synthesized from methionine through $S$-adenosyl-L-methionine and 1-aminocyclopropane-1-carboxylic acid (ACC), which are catalyzed by ACC synthase (ACS) and ACC oxidase (ACO) (Kende, 1993). The nitrate-dependent ethylene evolution and accumulation were accompanied by transient but significant increase of ACS and ACO, which are transcriptionally induced by the transferring to high nitrate $(10 \mathrm{mM})$. The inactivation of ACS and ACO by their antagonists alleviated LR growth defects. Nitrate-induced ethylene inhibited the growth of immature LRs, which is at a later development stage compared to ABA-induced LR inhibition.

Employing the combinations of Chl1-5 and nrt2.1-1 mutants and ethylene-insensitive mutants, etr1-3 and ein2-1, ethylene was demonstrated as an important modulator in the regulation of nitrate-dependent expression of the two main transporters, NRT1.1 (CHL1/NPF6.3) and NRT2.1 (Tian et al., 2009). Notably, in the comparable range of low nitrate $(0.5 \mathrm{mM})$, NRT2.1 promotes initiation of LR primordia, which is likely a different mechanism occurring at an early stage of LR development (Remans et al., 2006b). The ethylene-dependent regulation, or nitrate signaling relay (Krouk, 2016) observed here when seeding roots being challenged by high nitrate conditions, could be centered on NRT1.1 (CHL1/NPF6.3) whose expression is much more strongly affected. This signaling relay via ethylene might be part of the mechanism where NRT1.1 (CHL1/NPF6.3) mediates the repression of NRT2.1 between high-affinity transport mode and low-affinity transport mode (Muños et al., 2004; Krouk et al., 2006). Interestingly, transferring seedlings from high nitrate $(10 \mathrm{mM})$ to low nitrate $(0.1 \mathrm{mM})$ also caused a rapid burst of ethylene production measured on a whole-plant basis. NRT2.1 whose repression is relieved by NRT1.1 (CHL1/NPF6.3) under low nitrate concentration $(<0.5 \mathrm{mM})$ was singled out to be responsible for stimulating ethylene production (Zheng et al., 2013).

\section{NITRATE IN GIBBERELLIN BIOSYNTHESIS, TRANSPORT, AND SIGNALING}

Gibberellins are tetracyclic diterpenoid hormones. GAs are key endogenous regulators involved in seed germination, root and shoot elongation, flowering, and fruit patterning (Daviere et al., 2014; Tal et al., 2016). Much of the lead role of nitrate in dancing with hormones has been revealed in roots. Nevertheless, nitrate-hormone interaction certainly takes place in whole plants. For example, in the transition from vegetative growth to reproduction, earlier flowering was favored at low nitrate growth conditions rather than at high nitrate conditions. The major repressor of flowering in Arabidopsis, FLOWERING LOCUS C
$(F L C)$, is repressed and activators of flowering, FLOWERING LOCUS T (FT), LEAFY (LFY), and APETALA1 (AP1), are induced in low-nitrate conditions. Interacting with photoperiodand temperature- and GA-signaling pathways, nitrate regulates floral induction by communicating nutrient availability (CastroMarín et al., 2011; Kant et al., 2011; Liu et al., 2013). The low nitrate $(1 \mathrm{mM})$ was shown to transcriptionally induce expression of GA1, the main GA biosynthesis gene, therefore promoting bioactive GAs in various tissues of flowering plants. Along with GA1, nitrate also induced the expression of SUPPRESSOR OF OVEREXPRESSION OF CO 1 (SOC1), an integrator of the GA-dependent flowering pathway which coordinates all the endogenous pathways: GA, vernalization, autonomous, and photoperiod (Liu et al., 2013). The transcriptome of pre-starved Arabidopsis seedlings in response to nitrate re-addition (3

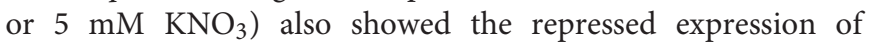
$G I D 1 B$, GA receptor and the induced expression of GATA, NITRATE-INDUCIBLE, CARBON-METABOLISM INVOLVED (GNC) and GNC-LIKE/CYTOKININ-RESPONSIVE GATA FACTOR1 (GNL/CGA1) TFs, negative regulators of GA signaling downstream from DELLA proteins and PHYTOCHROMEINTERACTING FACTORS (PIFs) (Wang et al., 2003, 2004; Scheible et al., 2004; Richter et al., 2010).

NPF3.1 expression in endodermis were found to be transcriptionally repressed by GA and promoted by ABA (Tal et al., 2016). NPF3.1 is a plasma membrane localized protein mediating nitrate and nitrite uptake (Sugiura et al., 2007; Leran et al., 2014). In addition, the experiments in $X$. oocytes showed that NPF3.1 is an active GA importer and it is also capable of transporting ABA. Another NPF protein, AIT3/NPF4.1, was found earlier to have ABA and GA transport activities (Kanno et al., 2012). NPF3.1 as such, is involved in two antagonistic hormone signaling in endodermal cells controlling root meristem size (Tal et al., 2016). Such an intimate interplay between nitrate, GA and ABA were also observed in determining seed dormancy and germination times (Alboresi et al., 2005; Chopin et al., 2007; Yan et al., 2016). GTR1/NPF2.10 was also proposed as a multifunctional transporter employed by the structurally distinct compounds glucosinolates, JA-Ile and GA, which promote stamen development via mediating bioactive GA transport (Saito et al., 2015).

\section{CONCLUSION}

Decades of nitrate research have given rise to new paradigms. By analogy with molecular oxygen $\left(\mathrm{O}_{2}\right)$ being an environmental morphogen in embryonic development and stem cell function in animals (Simon and Keith, 2008), and auxin being proposed as a plant morphogen (Bhalerao and Bennett, 2003; Esmon et al., 2006), nitrate could be a potent environmental morphogen in plants given the comprehensive nitrate transport, sensing, signaling and regulations at the level of the cell and organism (Wang et al., 2004, 2012; Bellegarde et al., 2017). Remarkably, less than $0.1 \%$ seed $\mathrm{N}$ is from nitrate (Chopin et al., 2007), which doesn't prevent nitrate from being a crucial signal and creating specific niches (Yan et al., 2016); and phloem-based 
transport of nitrate that represents only $1-10 \%$ of total $\mathrm{N}$ in the phloem sap, has a more morphogenetic role than a nutritional role in sink organs (Fan et al., 2009; Kiba et al., 2012; Hsu and Tsay, 2013; Bellegarde et al., 2017). The differential responses to extracellular nitrate availability while maintaining cellular homeostasis, especially steady-state ionic environment, are among the main morphogenetic effects in determining cell growth and identity in plants. At a more detailed level, the intercellular and intracellular gradients of nitrate could be responsible for diversified patterns of transient and sustained promotion or repression of expression levels of specific subsets of nitrate-responsive genes, which were observed in a variety of nitrate responses, including the PNR. Behind the whole-plant responses is that the changes of $\mathrm{N}$ status of the shoot could be potentially communicated to the root via the peaks and valleys of nitrate gradient and xylem- and phloem-based transport, serving for long-distance signaling (Bellegarde et al., 2017).

Why does nitrate signaling critically regulate so many types of phytohormones at so many levels? The localized hormone biosynthesis, deconjugation and degradation seem to be the primary connection between nitrate and hormones, for which solid molecular evidence has been increasingly found. Being an environmental cue and once being absorbed into plants, also becoming an environmental morphogen, nitrate transcriptionally regulates the metabolism and signaling of hormones at the whole plant level. Indeed, this regulatory process is highly context-dependent and spatiotemporal. Conversely, the hormones from nitrate-induced production, deconjugation and degradation, could act as mediators and/or modulators in $\mathrm{N}$-dependent signaling and regulation and provide feedback controls at the regional level. Notably, numerous hormone signaling and regulatory components were found to be transcriptionally activated by nitrate in certain contexts, suggesting that the signaling of the two morphogens is intertwined at multiple levels, if not all levels. The genome-wide transcriptome further revealed that the molecular conductors at the top-level of nitrate regulatory hierarchy could exert direct controls over hormonal pathways (Hervé et al., 2009; Danisman et al., 2012; Marchive et al., 2013; Guan et al., 2017; Liu et al., 2017), so that a variety of hormones are employed in propagation and amplification of nitrate signaling (Figure 2).

Intriguingly, cell-autonomous regulation by $\mathrm{N}$ in determining cell growth and fate is strongly indicated by TCP20-NLP6/7 regulatory nexus, which is involved in sensing nutrient status and transcriptional control of G2/M transition in cell cycle progression (Guan et al., 2017). Growing evidence suggests that there could exist PB1 domain-mediated interactions between

\section{REFERENCES}

Alboresi, A., Gestin, C., Leydecker, M. T., Bedu, M., Meyer, C., and Truong, H. N. (2005). Nitrate, a signal relieving seed dormancy in Arabidopsis. Plant Cell Environ. 28, 500-512. doi: 10.1111/j.1365-3040.2005.01292.x

Almagro, A., Lin, S. H., and Tsay, Y. F. (2008). Characterization of the Arabidopsis nitrate transporter NRT1.6 reveals a role of nitrate in early embryo development. Plant Cell 20, 3289-3299. doi: 10.1105/tpc.107.056788 nitrate and auxin signaling regulators upstream of TOR signaling, which are central in nutrient-growth process in plants (Xiong et al., 2013; Guan et al., 2017; Li et al., 2017). Moreover, the analogy between regulatory roles of TCP20 in response to nitrate availability and of TCP21/CHE in the circadian oscillator suggest a general TCP-dependent cell-autonomous mechanism for plant responses to variations in environmental cues, i.e., nutrients, light, and temperature (Pruneda-Paz et al., 2009; Guan et al., 2017). The intertwined coordination of cell autonomous and morphogen-gradient-dependent mechanisms is deeply conserved in eukaryotes, being well observed in the amoeba, Dictyostelium discoideum (Clay et al., 1995).

Hormones have long been regarded to provide an indispensable link between $\mathrm{N}$ and plant growth and development. However, among the most deeply conserved in plants, nitrate signaling and regulation with a highly organized transcriptional hierarchy are as crucial as hormonal signaling and regulation in growth, development and stress responses. The novel model that underlies substantial plant development and adaptive responses could involve other TCPs because of functional redundancy between TCP20 and its homologs. The classes I and II TCPs exert either coordinate or competitive regulation of transcription that could be essential for defining growth rate and organ development ( $\mathrm{Li}$ et al., 2005). The interaction between TCPs and hormone biosynthesis, transport, signaling and responses in growth, development and defense has been increasingly reported (Nicolas and Cubas, 2016). With TCPs in the picture, much extended interplay and convergent regulation between nitrate and hormone signaling will be expected.

In the past half century, $\mathrm{N}$ fertilizer is the main contributor to global crop production increases that support two billion more people on Earth. Nevertheless, NUE has become a major constraint on agricultural productivity and environmental sustainability worldwide. Understanding nitrate signaling and regulation and their interaction with hormones is central to meet the global challenges, which demands extensive research under the new paradigms.

\section{AUTHOR CONTRIBUTIONS}

The author confirms being the sole contributor of this work and approved it for publication.

\section{ACKNOWLEDGMENT}

I thank Dr. Nigel Crawford for discussions. Tamayo, K. P., et al. (2014). Systems approach identifies TGA1 and TGA4 transcription factors as important regulatory components of the nitrate response of Arabidopsis thaliana roots. Plant J. 80, 1-13. doi: 10.1111/tpj. 12618

Andrews, M. (1986). The partitioning of nitrate assimilation between root and shoot of higher plants. Plant Cell Environ. 9, 511-519. doi: 10.1111/1365-3040. ep11616228 
Araus, V., Vidal, E. A., Puelma, T., Alamos, S., Mieulet, D., Guiderdoni, E., et al. (2016). Members of BTB gene family of scaffold proteins suppress nitrate uptake and nitrogen use efficiency. Plant Physiol. 171, 1523-1532. doi: 10.1104/pp.15. 01731

Barrada, A., Montané, M.-H., Robaglia, C., and Menand, B. (2015). Spatial regulation of root growth: placing the plant TOR pathway in a developmental perspective. Int. J. Mol. Sci. 16, 19671-19697. doi: 10.3390/ijms1608 19671

Bellegarde, F., Gojon, A., and Martin, A. (2017). Signals and players in the transcriptional regulation of root responses by local and systemic $\mathrm{N}$ signaling in Arabidopsis thaliana. J. Exp. Bot. 68, 2553-2565. doi: 10.1093/jxb/erx062

Bhalerao, R. P., and Bennett, M. J. (2003). The case for morphogens in plants. Nat. Cell Biol. 5, 939-943. doi: 10.1038/ncb1103-939

Bleecker, A. B., and Kende, H. (2000). Ethylene: a gaseous signal molecule in plants. Annu. Rev. Cell Dev. Biol. 16, 1-18. doi: 10.1146/annurev.cellbio.16.1.1

Boer, D. R., Freire-Rios, A., van den Berg, W. A., Saaki, T., Manfield, I. W., Kepinski, S., et al. (2014). Structural basis for DNA binding specificity by the auxin-dependent ARF transcription factors. Cell 156, 577-589. doi: 10.1016/j. cell.2013.12.027

Bouguyon, E., Brun, F., Meynard, M., Kubes, M., Pervent, M., Leran, S., et al. (2015). Multiple mechanisms of nitrate sensing by Arabidopsis nitrate transceptor NRT1.1. Nat. Plants 1:15015. doi: 10.1038/nplants.2015.15

Camargo, A., Llamas, A., Schnell, R. A., Higuera, J. J., Gonzalez- Ballester, D., Lefebvre, P. A., et al. (2007). Nitrate signaling by the regulatory gene NIT2 in Chlamydomonas. Plant Cell 19, 3491-3503. doi: 10.1105/tpc.106. 045922

Castaings, L., Camargo, A., Pocholle, D., Gaudon, V., Texier, Y., Boutet-Mercey, S., et al. (2009). The nodule inception-like protein 7 modulates nitrate sensing and metabolism in Arabidopsis. Plant J. 57, 426-435. doi: 10.1111/j.1365-313X.2008. 03695.x

Castro-Marín, I., Loef, I., Bartetzko, L., Searle, I., Coupland, G., Stitt, M., et al. (2011). Nitrate regulates floral induction in Arabidopsis, acting independently of light, gibberellin and autonomous pathways. Planta 233, 539-552. doi: 10.1007/s00425-010-1316-5

Cerezo, M., Tillard, P., Filleur, S., Munos, S., Daniel-Vedele, F., and Gojon, A. (2001). Major alterations of the regulation of root NO3- uptake are associated with the mutation of Nrt2.1 and Nrt2.2 genes in Arabidopsis. Plant Physiol. 127, 262-271. doi: 10.1104/pp.127.1.262

Champigny, M. L., and Foyer, C. (1992). Nitrate activation of cytosolic protein kinases diverts photosynthetic carbon from sucrose to amino acid biosynthesis: basis for a new concept. Plant Physiol. 100, 7-12. doi: 10.1104/pp.100.1.7

Chapman, E. J., and Estelle, M. (2009). Mechanism of auxin-regulated gene expression in plants. Annu. Rev. Genet. 43, 265-285. doi: 10.1146/annurevgenet-102108-134148

Chardin, C., Girin, T., Roudier, F., Meyer, C., and Krapp, A. (2014). The plant RWP-RK transcription factors: key regulators of nitrogen responses and of gametophyte development. J. Exp. Bot. 65, 5577-5587. doi: 10.1093/jxb/eru261

Chen, Q., Dai, X., De-Paoli, H., Cheng, Y., Takebayashi, Y., Kasahara, H., et al. (2014). Auxin overproduction in shoots cannot rescue auxin deficiencies in Arabidopsis roots. Plant Cell Physiol. 55, 1072-1079. doi: 10.1093/pcp/pcu039

Cheng, C.-L., Dewdney, J., Nam, H.-G., Den Boer, B. G. W., and Goodman, H. M. (1988). A new locus (NIA1) in Arabidopsis thaliana encoding nitrate reductase. EMBO J. 7, 3309-3314.

Cheng, Y., Dai, X., and Zhao, Y. (2006). Auxin biosynthesis by the YUCCA flavin monooxygenases controls the formation of floral organs and vascular tissues in Arabidopsis. Genes Dev. 20, 1790-1799. doi: 10.1101/gad.1415106

Cheng, Y., Dai, X., and Zhao, Y. (2007). Auxin synthesized by the YUCCA flavin monooxygenases is essential for embryogenesis and leaf formation in Arabidopsis. Plant Cell 19, 2430-2439. doi: 10.1105/tpc.107.053009

Chiba, Y., Shimizu, T., Miyakawa, S., Kanno, Y., Koshiba, T., Kamiya, Y., et al. (2015). Identification of Arabidopsis thaliana NRT1/PTR family (NPF) proteins capable of transporting plant hormones. J. Plant Res. 128, 679-686. doi: 10.1007/s10265-015-0710-2

Chiu, C. C., Lin, C. S., Hsia, A. P., Su, R. C., Lin, H. L., and Tsay, Y. F. (2004). Mutation of a nitrate transporter, AtNRT1:4, results in a reduced petiole nitrate content and altered leaf development. Plant Cell Physiol. 45, 1139-1148. doi: $10.1093 / \mathrm{pcp} / \mathrm{pch} 143$
Chopin, F., Orsel, M., Dorbe, M. F., Chardon, F., Truong, H. N., Miller, A. J., et al. (2007). The Arabidopsis ATNRT2.7 nitrate transporter controls nitrate content in seeds. Plant Cell 19, 1590-1602. doi: 10.1105/tpc.107.050542

Clay, J. L., Ammann, R. A., and Gomer, R. H. (1995). Initial cell type choice in a simple eukaryote: Cell-autonomous or morphogen-gradient dependent? Dev. Biol. 172, 665-674. doi: 10.1006/dbio.1995.8045

Crawford, N. M. (1995). Nitrate: nutrient and signal for plant growth. Plant Cell 7, 859-868. doi: 10.1105/tpc.7.7.859

Crawford, N. M., and Forde, B. (2002). Molecular and developmental biology of inorganic nitrogen nutrition. Arabidopsis Book 1:e0011. doi: 10.1199/tab.0011

Crawford, N. M., and Glass, A. D. M. (1998). Molecular and physiological aspects of nitrate uptake in plants. Trends Plant Sci. 3, 389-395. doi: 10.1016/S13601385(98)01311-9

Cubas, P., Lauter, N., Doebley, J., and Coen, E. (1999). The TCP domain: a motif found in proteins regulating plant growth and development. Plant J. 18, 215-222. doi: 10.1046/j.1365-313X.1999.00444.x

Danisman, S., Van Der Wal, F., Dhondt, S., Waites, R., De Folter, S., Bimbo, A., et al. (2012). Arabidopsis class I and class II TCP transcription factors regulate jasmonic acid metabolism and leaf development antagonistically. Plant Physiol. 159, 1511-1523. doi: 10.1104/pp.112.200303

Daviere, J. M., Wild, M., Regnault, T., Baumberger, N., Eisler, H., Genschik, P., et al. (2014). Class I TCP-DELLA interactions in inflorescence shoot apex determine plant height. Curr. Biol. 24, 1923-1928. doi: 10.1016/j.cub.2014.07.012

De Angeli, A., Monachello, D., Ephritikhine, G., Frachisse, J. M., Thomine, S., Gambale, F., et al. (2006). The nitrate/proton antiporter AtCLCa mediates nitrate accumulation in plant vacuoles. Nature 442, 939-942. doi: 10.1038/ nature 05013

De Smet, I., Signora, L., Beeckman, T., Foyer, C. H., and Zhang, H. (2003). An abscisic acid-sensitive checkpoint in lateral root development in Arabidopsis. Plant J. 33, 543-555. doi: 10.1046/j.1365-313X.2003.01652.x

Deak, K. I., and Malamy, J. (2005). Osmotic regulation of root system architecture. Plant J. 43, 17-28. doi: 10.1111/j.1365-313X.2005.02425.x

Desikan, R., Griffiths, R., Hancock, J., and Neill, S. (2002). A new role for an old enzyme: nitrate reductase-mediated nitric oxide generation is required for abscisic acid-induced stomatal closure in Arabidopsis thaliana. Proc. Natl. Acad. Sci. U.S.A. 99, 16314-16318. doi: 10.1073/pnas.252461999

Drew, M. C., Saker, L. R., and Ashley, T. W. (1973). Nutrient supply and the growth of the seminal root system in barley. Part I. The effect of nitrate concentration on the growth of axes and laterals. J. Exp. Bot. 24, 1189-1202. doi: $10.1093 / \mathrm{jxb} / 24.6 .1189$

Ecker, J. R. (1995). The ethylene signal transduction pathway in plants. Science 268, 667-675. doi: 10.1126/science.7732375

Esmon, C. A., Tinsley, A. G., Ljung, K., Sandberg, G., Hearne, L. B., and Liscum, E. (2006). A gradient of auxin and auxin-dependent transcription precedes tropic growth responses. Proc. Natl. Acad. Sci. U.S.A. 103, 236-241. doi: 10.1073/pnas. 0507127103

Fagard, M., Launay, A., Clément, G., Courtial, J., Dellagi, A., Farjad, M., et al. (2014). Nitrogen metabolism meets phytopathology. J Exp. Bot. 65, 5643-5656. doi: $10.1093 /$ jxb/eru323

Fan, S. C., Lin, C. S., Hsu, P. K., Lin, S. H., and Tsay, Y. F. (2009). The Arabidopsis nitrate transporter NRT1.7, expressed in phloem, is responsible for source-tosink remobilization of nitrate. Plant Cell 21, 2750-2761. doi: 10.1105/tpc.109. 067603

Fan, X., Tang, Z., Tan, Y., Zhang, Y., Luo, B., Yang, M., et al. (2016). Overexpression of a pH-sensitive nitrate transporter in rice increases crop yields. Proc. Natl. Acad. Sci. U.S.A. 113, 7118-7123. doi: 10.1073/pnas.1525184113

Footitt, S., Douterelo-Soler, I., Clay, H., and Finch-Savage, W. E. (2011). Dormancy cycling in Arabidopsis seeds is controlled by seasonally distinct hormone-signaling pathways. Proc. Natl. Acad. Sci. U.S.A. 108, 20236-20241. doi: 10.1073/pnas.1116325108

Footitt, S., Huang, Z. Y., Clay, H. A., Mead, A., and Finch-Savage, W. E. (2013). Temperature, light and nitrate sensing coordinate Arabidopsis seed dormancy cycling, resulting in winter and summer annual phenotypes. Plant J. 74, 1003-1015. doi: 10.1111/tpj.12186

Forde, B. G. (2000). Nitrate transporters in plants: structure, function and regulation. Biochim. Biophys. Acta 1465, 219-235. doi: 10.1016/S0005-2736(00) 00140-1 
Forde, B. G. (2002). Local and long-range signaling pathways regulating plant responses to nitrate. Annu. Rev. Plant Biol. 53, 203-224. doi: 10.1146/annurev. arplant.53.100301.135256

Friml, J., Vieten, A., Sauer, M., Weijers, D., Schwarz, H., Hamann, T., et al. (2003). Efflux-dependent auxin gradients establish the apical-basal axis of Arabidopsis. Nature 426, 147-153. doi: 10.1038/nature02085

Fu, H.-H., and Luan, S. (1998). AtKUP1: a dual-affinity K+ transporter from Arabidopsis. Plant Cell 10, 63-74. doi: 10.1105/tpc.10.1.63

Fukaki, H., and Tasaka, M. (2009). Hormone interactions during lateral root formation. Plant Mol. Biol. 69, 437-449. doi: 10.1007/s11103-008-9417-2

Geiger, D., Maierhofer, T., Al-Rasheid, K. A., Scherzer, S., Mumm, P., Liese, A., et al. (2011). Stomatal closure by fast abscisic acid signaling is mediated by the guard cell anion channel SLAH3 and the receptor RCAR1. Sci. Signal. 4:ra32. doi: 10.1126/scisignal.2001346

Girin, T., Lejay, L., Wirth, J., Widiez, T., Palenchar, P. M., Nazoa, P., et al. (2007). Identification of a $150 \mathrm{bp}$ cis-acting element of the AtNRT2.1 promoter involved in the regulation of gene expression by the $\mathrm{N}$ and $\mathrm{C}$ status of the plant. Plant Cell Environ. 30, 1366-1380. doi: 10.1111/j.1365-3040.2007.01712.x

Gojon, A., Krouk, G., Perrine-Walker, F., and Laugier, E. (2011). Nitrate transceptor(s) in plants. J. Exp. Bot. 62, 2299-2308. doi: 10.1093/jxb/erq419

Guan, P., Ripoll, J.-J., Wang, R., Vuong, L., Bailey-Steinitz, L. J., Ye, D., et al. (2017). Interacting TCP and NLP transcription factors control plant responses to nitrate availability. Proc. Natl. Acad. Sci. U.S.A. 114, 2419-2424. doi: 10.1073/ pnas. 1615676114

Guan, P., Wang, R., Nacry, P., Breton, G., Kay, S. A., Pruneda-Paz, J. L., et al. (2014). Nitrate foraging by Arabidopsis roots is mediated by the transcription factor TCP20 through the systemic signaling pathway. Proc. Natl. Acad. Sci. U.S.A. 111, 15267-15272. doi: 10.1073/pnas.1411375111

Guilfoyle, T. J. (2015). The PB1 domain in auxin response factor and Aux/IAA proteins: a versatile protein interaction module in the auxin response. Plant Cell 27, 33-43. doi: 10.1105/tpc.114.132753

Guo, F. Q., Wang, R., and Crawford, N. M. (2002). The Arabidopsis dual-affinity nitrate transporter gene AtNRT1.1 (CHL1) is regulated by auxin in both shoots and roots. J. Exp. Bot. 53, 835-844. doi: 10.1093/jexbot/53.370.835

Guo, F. Q., Yang, J., and Crawford, N. M. (2003). The nitrate transporter AtNRT1.1 (CHL1) functions in stomatal opening and contributes to drought susceptibility in Arabidopsis. Plant Cell 15, 107-117. doi: 10.1105/tpc.006312

Gutierrez, C. (2009). The Arabidopsis cell division cycle. Arabidopsis Book. 7:e0120. doi: $10.1199 /$ tab.0120

Hashimoto, K., Eckert, C., Anschutz, U., Scholz, M., Held, K., Waadt, R., et al. (2012). Phosphorylation of calcineurin B-like (CBL) calcium sensor proteins by their CBL-interacting protein kinases (CIPKs) is required for full activity of CBL-CIPK complexes toward their target proteins. J. Biol. Chem. 287, 7956-7968. doi: 10.1074/jbc.M111.279331

Hervé, C., Dabos, P., Bardet, C., Jauneau, A., Auriac, M. C., Ramboer, A., et al. (2009). In vivo interference with AtTCP20 function induces severe plant growth alterations and deregulates the expression of many genes important for development. Plant Physiol. 149, 1462-1477. doi: 10.1104/pp.108.126136

Himanen, K., Boucheron, E., Vanneste, S., de Almeida Engler, J., Inze', D., and Beeckman, T. (2002). Auxin-mediated cell cycle activation during early lateral root initiation. Plant Cell 14, 2339-2351. doi: 10.1105/tpc.004960

Himanen, K., Vuylsteke, M., Vanneste, S., Vercruysse, S., Boucheron, E., Alard, P., et al. (2004). Transcript profiling of early lateral root initiation. Proc. Natl. Acad. Sci. U.S.A 101, 5146-5151. doi: 10.1073/pnas.0308702101

Ho, C. H., Lin, S. H., Hu, H. C., and Tsay, Y. F. (2009). CHL1 functions as a nitrate sensor in plants. Cell 138, 1184-1194. doi: 10.1016/j.cell.2009.07.004

Howitt, S. M., and Udvardi, M. K. (1999). Structure, function and regulation of ammonium transporters in plants. Biochim. Biophys. Acta 1465, 152-170. doi: 10.1016/S0005-2736(00)00136-X

Hsu, P. K., and Tsay, Y. F. (2013). Two phloem nitrate transporters, NRT1.11 and NRT1.12, are important for redistributing xylem-borne nitrate to enhance plant growth. Plant Physiol. 163, 844-856. doi: 10.1104/pp.113.226563

Hu, H. C., Wang, Y. Y., and Tsay, Y. F. (2009). AtCIPK8, a CBL-interacting protein kinase, regulates the low-affinity phase of the primary nitrate response. Plant J. 57, 264-278. doi: 10.1111/j.1365-313X.2008.03685.x

Huang, N. C., Liu, K. H., Lo, H. J., and Tsay, Y. F. (1999). Cloning and functional characterization of an Arabidopsis nitrate transporter gene that encodes a constitutive component of low-affinity uptake. Plant Cell 11, 1381-1392. doi: 10.1105/tpc.11.8.1381

Ioio, R. D., Linhares, F. S., Scacchi, E., Casamitjana-Martinez, E., Heidstra, R., Costantino, P., et al. (2007). Cytokinins determine Arabidopsis root meristem size by controlling cell differentiation. Curr. Biol. 17, 678-682. doi: 10.1016/j. cub.2007.02.047

Kang, J., Yu, H., Tian, C., Zhou, W., Li, C., Jiao, Y., et al. (2014). Suppression of photosynthetic gene expression in roots is required for sustained root growth under phosphate deficiency. Plant Physiol. 165, 1156-1170. doi: 10.1104/pp.114. 238725

Kanno, Y., Hanada, A., Chiba, Y., Ichikawa, T., Nakazawa, M., Matsui, M., et al. (2012). Identification of an abscisic acid transporter bifunctional screening using the receptor complex as a sensor. Proc. Natl. Acad. Sci. U.S.A 109, 9653-9658. doi: 10.1073/pnas.1203567109

Kant, S., Peng, M., and Rothstein, S. J. (2011). Genetic regulation by NLA and microRNA827 for maintaining nitrate-dependent phosphate homeostasis in Arabidopsis. PLOS Genet. 7:e1002021. doi: 10.1371/journal.pgen. 1002021

Karve, R., Suárez-Román, F., and Iyer-Pascuzzi, A. S. (2016). The transcription factor NIN-LIKE PROTEIN7 controls border-like cell release. Plant Physiol. 171, 2101-2111. doi: 10.1104/pp.16.00453

Kende, H. (1993). Ethylene biosynthesis. Annu. Rev. Plant Physiol. Plant Mol. Biol. 44, 283-307. doi: 10.1146/annurev.pp.44.060193.001435

Kiba, T., Feria-Bourrellier, A. B., Lafouge, F., Lezhneva, L., Boutet-Mercey, S., Orsel, M., et al. (2012). The Arabidopsis nitrate transporter NRT2.4 plays a double role in roots and shoots of nitrogen-starved plants. Plant Cell 24, 245-258. doi: 10.1105/tpc.111.092221

Kiba, T., Kudo, T., Kojima, M., and Sakakibara, H. (2010). Hormonal control of nitrogen acquisition: roles of auxin, abscisic acid, and cytokinin. J. Exp. Bot. 62, 1399-1409. doi: 10.1093/jxb/erq410

Kim, E. J., Kwak, J. M., Uozumi, N., and Schroeder, J. I. (1998). AtKUP1: an Arabidopsis gene encoding high-affinity potassium transport activity. Plant Cell 10, 51-62. doi: 10.1105/tpc.10.1.51

Konishi, M., and Yanagisawa, S. (2013). Arabidopsis NIN-like transcription factors have a central role in nitrate signalling. Nat. Commun. 4:1617. doi: 10.1038/ ncomms 2621

Konishi, M., and Yanagisawa, S. (2010). Identification of a nitrate-responsive ciselement in the Arabidopsis NIR1 promoter defines the presence of multiple cis-regulatory elements for nitrogen response. Plant J. 63, 269-282. doi: 10. 1111/j.1365-313X.2010.04239.x

Korasick, D. A., Westfall, C. S., Lee, S. G., Nanao, M. H., Dumas, R., Hagen, G., et al. (2014). Molecular basis for AUXIN RESPONSE FACTOR protein interaction and the control of auxin response repression. Proc. Natl. Acad. Sci. U.S.A. 111, 5427-5432. doi: 10.1073/pnas.1400074111

Kotur, Z., and Glass, A. D. (2015). A $150 \mathrm{kDa}$ plasma membrane complex of AtNRT2.5 and AtNAR2.1 is the major contributor to constitutive high-affinity nitrate influx in Arabidopsis thaliana. Plant Cell Environ. 38, 1490-1502. doi: $10.1111 /$ pce. 12496

Kotur, Z., Mackenzie, N., Ramesh, S., Tyerman, S. D., Kaiser, B. N., and Glass, A. D. (2012). Nitrate transport capacity of the Arabidopsis thaliana NRT2 family members and their interactions with AtNAR2.1. New Phytol 194, 724-731. doi: 10.1111/j.1469-8137.2012.04094.x

Krapp, A. (2015). Plant nitrogen assimilation and its regulation: a complex puzzle with missing pieces. Curr. Opin. Plant Biol. 25, 115-122. doi: 10.1016/j.pbi.2015. 05.010

Krapp, A., David, L. C., Chardin, C., Girin, T., Marmagne, A., Leprince, A. S., et al. (2014). Nitrate transport and signalling in Arabidopsis. J. Exp. Bot. 65, 789-798. doi: $10.1093 / \mathrm{jxb} / \mathrm{eru001}$

Krouk, G. (2016). Hormones and nitrate: a two-way connection. Plant Mol. Biol. 91, 599-606. doi: 10.1007/s11103-016-0463-x

Krouk, G., Crawford, N. M., Coruzzi, G. M., and Tsay, Y.-F. (2010a). Nitrate signaling: adaptation to fluctuating environments. Curr. Opin. Plant Biol. 13, 265-272. doi: 10.1016/j.pbi.2009.12.003

Krouk, G., Lacombe, B., Bielach, A., Perrine-Walker, F., Malinska, K., Mounier, E., et al. (2010b). Nitrate-regulated auxin transport by NRT1.1 defines a mechanism for nutrient sensing in plants. Dev. Cell 18, 927-937. doi: 10.1016/j.devcel.2010. 05.008 
Krouk, G., Mirowski, P., LeCun, Y., Shasha, D. E., and Coruzzi, G. M. (2010c). Predictive network modeling of the high-resolution dynamic plant transcriptome in response to nitrate. Genome Biol. 11:R123. doi: 10.1186/gb2010-11-12-r123

Krouk, G., Ruffel, S., Gutierrez, R. A., Gojon, A., Crawford, N. M., Coruzzi, G. M., et al. (2011). A framework integrating plant growth with hormones and nutrients. Trends Plant Sci. 16, 178-182. doi: 10.1016/j.tplants.2011.02.004

Krouk, G., Tillard, P., and Gojon, A. (2006). Regulation of the high-affinity NO3uptake system by NRT1.1-mediated NO3- demand signaling in Arabidopsis. Plant Physiol. 142, 1075-1086. doi: 10.1104/pp.106.087510

Kushiro, T., Okamoto, M., Nakabayashi, K., Yamagishi, K., Kitamura, S., Asami, T., et al. (2004). The Arabidopsis cytochrome P450CYP707A encodes ABA 8'hydroxylases: key enzymes in ABA catabolism. EMBO J. 23, 1647-1656. doi: $10.1038 /$ sj.emboj.7600121

Lamb, P., and McKnight, S. L. (1991). Diversity and specificity in transcriptional regulation: the benefits of heterotypic dimerization. Trends Biochem. Sci. 16, 417-422. doi: 10.1016/0968-0004(91)90167-T

Laplaze, L., Benkova, E., Casimiro, I., Maes, L., Vanneste, S., Swarup, R., et al. (2007). Cytokinins act directly on lateral root founder cells to inhibit root initiation. Plant Cell 19, 3889-3900. doi: 10.1105/tpc.107.055863

Leran, S., Edel, K. H., Pervent, M., Hashimoto, K., Corratge-Faillie, C., Offenborn, J. N., et al. (2015). Nitrate sensing and uptake in Arabidopsis are enhanced by $\mathrm{ABI}$, a phosphatase inactivated by the stress hormone abscisic acid. Sci. Signal. 8:ra43. doi: 10.1126/scisignal.aaa4829

Leran, S., Varala, K., Boyer, J. C., Chiurazzi, M., Crawford, N., DanielVedele, F., et al. (2014). A unified nomenclature of NITRATE TRANSPORTER 1/PEPTIDE TRANSPORTER family members in plants. Trends Plant Sci. 19, 5-9. doi: 10.1016/j.tplants.2013.08.008

Lezhneva, L., Kiba, T., Feria-Bourrellier, A. B., Lafouge, F., Boutet-Mercey, S., Zoufan, P., et al. (2014). The Arabidopsis nitrate transporter NRT2.5 plays a role in nitrate acquisition and remobilization in nitrogen-starved plants. Plant J. 80, 230-241. doi: 10.1111/tpj.12626

Li, C., Potuschak, T., Colón-Carmona, A., Gutiérrez, R. A., and Doerner, P. (2005). Arabidopsis TCP20 links regulation of growth and cell division control pathways. Proc. Natl. Acad. Sci. U.S.A. 102, 12978-12983. doi: 10.1073/pnas. 0504039102

Li, H., Shen, J. J., Zheng, Z. L., Lin, Y., and Yang, Z. (2001). The Rop GTPase switch controls multiple developmental processes in Arabidopsis. Plant Physiol. 126, 670-684. doi: 10.1104/pp.126.2.670

Li, J. Y., Fu, Y. L., Pike, S. M., Bao, J., Tian, W., Zhang, Y., et al. (2010). The Arabidopsis nitrate transporter NRT1.8 functions in nitrate removal from the xylem sap and mediates cadmium tolerance. Plant Cell 22, 1633-1646. doi: 10.1105/tpc.110.075242

Li, W., Wang, Y., Okamoto, M., Crawford, N. M., Siddiqi, M. Y., and Glass, A. D. (2007). Dissection of the AtNRT2.1:AtNRT2.2 inducible high-affinity nitrate transporter gene cluster. Plant Physiol. 143, 425-433. doi: 10.1104/pp. 106.091223

Li, X., Cai, W., Liu, Y., Li, H., Fu, L., Liu, Z., et al. (2017). Differential TOR activation and cell proliferation in Arabidopsis root and shoot apexes. Proc. Natl. Acad. Sci. U.S.A. 114, 2765-2770. doi: 10.1073/pnas.1618782114

Lin, S. H., Kuo, H. F., Canivenc, G., Lin, C. S., Lepetit, M., Hsu, P. K., et al. (2008). Mutation of the Arabidopsis NRT1.5 nitrate transporter causes defective root-to-shoot nitrate transport. Plant Cell 20, 2514-2528. doi: 10.1105/tpc.108. 060244

Linares, J. F., Duran, A., Reina-Campos, M., Aza-Blanc, P., Campos, A., Moscat, J., et al. (2015). Amino acid activation of mTORC1 by a PB1-domain-driven kinase complex cascade. Cell Rep. 12, 1339-1352. doi: 10.1016/j.celrep.2015. 07.045

Little, D. Y., Rao, H., Oliva, S., Daniel-Vedele, F., Krapp, A., and Malamy, J. E. (2005). The putative high-affinity nitrate transporter NRT2.1 represses lateral root initiation in response to nutritional cues. Proc. Natl. Acad. Sci. U.S.A. 102, 13693-13698. doi: 10.1073/pnas.0504219102

Liu, K. H., Huang, C. Y., and Tsay, Y. F. (1999). CHL1 is a dual-affinity nitrate transporter of Arabidopsis involved in multiple phases of nitrate uptake. Plant Cell 11, 865-874. doi: 10.1105/tpc.11.5.865

Liu, K. H., Niu, Y., Konishi, M., Wu, Y., Du, H., Chung, H. S., et al. (2017). Discovery of nitrate-CPK-NLP signalling in central nutrient-growth networks. Nature 545, 311-316. doi: 10.1038/nature22077
Liu, K. H., and Tsay, Y. F. (2003). Switching between the two action modes of the dual-affinity nitrate transporter CHL1 by phosphorylation. EMBO J. 22, 1005-1013. doi: 10.1093/emboj/cdg118

Liu, T., Li, Y., Ren, J., Qian, Y., Yang, X., Duan, W., et al. (2013). Nitrate or $\mathrm{NaCl}$ regulates floral induction in Arabidopsis thaliana. Biologia 68, 215-222. doi: 10.2478/s11756-013-0004-x

Ma, W., Li, J., Qu, B., He, X., Zhao, X., Li, B., et al. (2014). Auxin biosynthetic gene TAR2 is involved in low nitrogen mediated reprogramming of root architecture in Arabidopsis. Plant J. 78, 70-79. doi: 10.1111/tpj.12448

Malamy, J. (2005). Intrinsic and environmental response pathways that regulate root system architecture. Plant Cell Environ. 28, 67-77. doi: 10.1111/j.13653040.2005.01306.x

Manassero, N. G., Viola, I. L., Welchen, E., and Gonzalez, D. H. (2013). TCP transcription factors: architectures of plant form. Biomol. Concepts 4, 111-127. doi: 10.1515/bmc-2012-0051

Mangan, S., and Alon, U. (2003). Structure and function of the feed-forward loop network motif. Proc. Natl. Acad. Sci. U.S.A. 100, 11980-11985. doi: 10.1073/ pnas. 2133841100

Marchive, C., Roudier, F., Castaings, L., Brehaut, V., Blondet, E., Colot, V., et al. (2013). Nuclear retention of the transcription factor NLP7 orchestrates the early response to nitrate in plants. Nat. Commun. 4:1713. doi: 10.1038/ncomms 2650

Martinière, A., Desbrosses, G., Sentenac, H., and Paris, N. (2013). Development and properties of genetically encoded pH sensors in plants. Front. Plant Sci. 4:523. doi: $10.3389 /$ fpls.2013.00523

Martín-Trillo, M., and Cubas, P. (2010). TCP genes: a family snapshot ten years later. Trends Plant Sci. 15, 31-39. doi: 10.1016/j.tplants.2009.11.003

Masclaux-Daubresse, C., Daniel-Vedele, F., Dechorgnat, J., Chardon, F., Gaufichon, L., and Suzuki, A. (2010). Nitrogen uptake, assimilation and remobilization in plants: challenges for sustainable and productive agriculture. Ann. Bot. 105, 1141-1157. doi: 10.1093/aob/mcq028

Mayer, C., Zhao, J., Yuan, X., and Grummt, I. (2004). mTOR-dependent activation of the transcription factor TIF-IA links rRNA synthesis to nutrient availability. Genes Dev. 18, 423-434. doi: 10.1101/gad.285504

Medici, A., and Krouk, G. (2014). The primary nitrate response: a multifaceted signalling pathway. J. Exp. Bot. 65, 5567-5576. doi: 10.1093/jxb/eru245

Medici, A., Marshall-Colon, A., Ronzier, E., Szponarski, W., Wang, R., Gojon, A., et al. (2015). AtNIGT1/HRS1 integrates nitrate and phosphate signals at the Arabidopsis root tip. Nat. Commun. 6:6274. doi: 10.1038/ncomms7274

Miller, A. J., and Cramer, M. D. (2004). Root nitrogen acquisition and assimilation. Plant Soil 274, 1-36. doi: 10.1007/s11104-004-0965-1

Miller, A. J., Fan, X., Orsel, M., Smith, S. J., and Wells, D. M. (2007). Nitrate transport and signalling. J. Exp. Bot. 58, 2297-2306. doi: 10.1093/jxb/erm066

Miller, A. J., Fan, X., Shen, Q., and Smith, S. J. (2008). Amino acids and nitrate as signals for the regulation of nitrogen acquisition. J. Exp. Bot. 59, 111-119. doi: $10.1093 / \mathrm{jxb} / \mathrm{erm} 208$

Miller, A. J., and Smith, S. J. (1996). Nitrate transport and compartmentation in cereal root cells. J. Exp. Bot. 47, 843-854. doi: 10.1093/jxb/47.7.843

Miller, A. J., and Smith, S. J. (2008). Cytosolic nitrate ion homeostasis: could it have a role in sensing nitrogen status? Ann. Bot. 101, 485-489. doi: 10.1093/ $\mathrm{aob} / \mathrm{mcm} 313$

Miyawaki, K., Matsumoto-Kitano, M., and Kakimoto, T. (2004). Expression of cytokinin biosynthetic isopentenyltransferase genes in Arabidopsis: tissue specificity and regulation by auxin, cytokinin, and nitrate. Plant J. 37, 128-138. doi: 10.1046/j.1365-313X.2003.01945.x

Mok, D. W., and Mok, M. C. (2001). Cytokinin metabolism and action. Annu. Rev. Plant Physiol. Plant Mol. Biol. 52, 89-118. doi: 10.1146/annurev.arplant.52.1.89

Morère-Le, Paven MC, Viau, L., Hamon, A., Vandecasteele, C., Pellizzaro, A., Bourdin, C., et al. (2011). Characterization of a dual-affinity nitrate transporter MtNRT1.3 in the model legume Medicago truncatula. J. Exp. Bot 62, 5595-5605. doi: 10.1093/jxb/err243

Mounier, E., Pervent, M., Ljung, K., Gojon, A., and Nacry, P. (2014). Auxinmediated nitrate signalling by NRT1.1 participates in the adaptive response of Arabidopsis root architecture to the spatial heterogeneity of nitrate availability. Plant Cell Environ. 37, 162-174. doi: 10.1111/pce.12143

Muños, S., Cazettes, C., Fizames, C., Gaymard, F., Tillard, P., Lepetit, M., et al. (2004). Transcript profiling in the chl1-5 mutant of Arabidopsis reveals a role of the nitrate transporter NRT1.1 in the regulation of another nitrate transporter, NRT2.1. Plant Cell 16, 2433-2447. doi: 10.1105/tpc.104.024380 
Nacry, P., Bouguyon, E., and Gojon, A. (2013). Nitrogen acquisition by roots: physiological and developmental mechanisms ensuring plant adaptation to a fluctuating resource. Plant Soil 370, 1-29. doi: 10.1007/s11104-013$1645-9$

Nicolas, M., and Cubas, P. (2016). TCP factors: new kids on the signaling block. Curr. Opin. Plant Biol. 33, 33-41. doi: 10.1016/j.pbi.2016.05.006

Normanly, J. (2010). Approaching cellular and molecular resolution of auxin biosynthesis and metabolism. Cold Spring Harb. Perspect. Biol 2:a001594. doi: $10.1101 /$ cshperspect.a001594

Nour-Eldin, H. H., Andersen, T. G., Burow, M., Madsen, S. R., Jørgensen, M. E., Olsen, C. E. et al. (2012). NRT/PTR transporters are essential for translocation of glucosinolate defence compounds to seeds. Nature 488, 531-534. doi: 10. 1038/nature11285

Nunes-Nesi, A., Fernie, A. R., and Stitt, M. (2010). Metabolic and signaling aspects underpinning the regulation of plant carbon nitrogen interactions. Mol. Plant 3, 973-996. doi: 10.1093/mp/ssq049

O’Brien, J. A., Vega, A., Bouguyon, E., Krouk, G., Gojon, A., Coruzzi, G., et al. (2016). Nitrate transport, sensing, and responses in plants. Mol. Plant 9, 837-856. doi: 10.1016/j.molp.2016.05.004

Ohkubo, Y., Tanaka, M., Tabata, R., Ogawa-Ohnishi, M., and Matsubayashi, Y. (2017). Shoot-to-root mobile polypeptides involved in systemic regulation of nitrogen acquisition. Nat. Plants 3:17029. doi: 10.1038/nplants.2017.29

Okamoto, S., Shinohara, H., Mori, T., Matsubayashi, Y., and Kawaguchi, M. (2013). Root-derived CLE glycopeptides control nodulation by direct binding to HAR1 receptor kinase. Nat. Commun. 4:2191. doi: 10.1038/ncomms3191

O’Malley, R. C., Huang, S. S., Song, L., Lewsey, M. G., Bartlett, A., Nery, J. R., et al. (2016). Cistrome and epicistrome features shape the regulatory DNA landscape. Cell 165, 1280-1292. doi: 10.1016/j.cell.2016.04.038

Ondzighi-Assoume, C. A., Chakraborty, S., and Harris, J. M. (2016). Environmental nitrate stimulates root tip abscisic acid accumulation via release from inactive stores. Plant Cell 28, 729-745. doi: 10.1105/tpc.15.00946

Overvoorde, P., Fukaki, H., and Beeckman, T. (2010). Auxin control of root development. Cold Spring Harb. Perspect. Biol. 2:a001537. doi: 10.1101/ cshperspect.a001537

Para, A., Li, Y., Marshall-Colon, A., Varala, K., Francoeur, N. J., Moran, T. M., et al. (2014). Hit-and-run transcriptional control by bZIP1 mediates rapid nutrient signaling in Arabidopsis. Proc. Natl. Acad. Sci. U.S.A. 111, 10371-10376. doi: 10.1073/pnas.1404657111

Pawson, T., and Nash, P. (2000). Protein-protein interactions define specificity in signal transduction. Genes Dev. 14, 1027-1047. doi: 10.1101/gad.14.9.1027

Perrot-Rechenmann, C. (2010). Cellular responses to auxin: division versus expansion. Cold Spring Harb. Perspect. Biol. 2:a001446. doi: 10.1101/ cshperspect.a001446

Pinon, V., Prasad, K., Grigg, S. P., Sanchez-Perez, G. F., and Scheres, B. (2013). Local auxin biosynthesis regulation by PLETHORA transcription factors controls phyllotaxis in Arabidopsis. Proc. Natl Acad. Sci. U.S.A. 110, 1107-1112. doi: $10.1073 /$ pnas. 1213497110

Powers, T., and Walter, P. (1999). Regulation of ribosome biogenesis by the rapamycin-sensitive TOR-signaling pathway in saccharomyces cerevisiae. Mol. Biol. Cell. 10, 987-1000. doi: 10.1091/mbc.10.4.987

Pruneda-Paz, J. L., Breton, G., Para, A., and Kay, S. A. (2009). A functional genomics approach reveals CHE as a component of the Arabidopsis circadian clock. Science 323, 1481-1485. doi: 10.1126/science.1167206

Raines, T., Shanks, C., Cheng, C. Y., McPherson, D., Argueso, C. T., Kim, H. J., et al. (2016). The cytokinin response factors modulate root and shoot growth and promote leaf senescence in Arabidopsis. Plant J. 85, 134-147. doi: 10.1111/ tpj.13097

Ramireddy, E., Chang, L., and Schmülling, T. (2014). Cytokinin as a mediator for regulating root system architecture in response to environmental cues. Plant Signal. Behav. 9:e27771. doi: 10.4161/psb.27771

Rani Debi, B., Taketa, S., and Ichii, M. (2005). Cytokinin inhibits lateral root initiation but stimulates lateral root elongation in rice (Oryza sativa). J. Plant Physiol. 162, 507-515. doi: 10.1016/j.jplph.2004.08.007

Rashotte, A. M., Mason, M. G., Hutchison, C. E., Ferreira, F. J., Schaller, G. E., and Kieber, J. J. (2006). A subset of Arabidopsis AP2 transcription factors mediates cytokinin responses in concert with a two-component pathway. Proc. Natl. Acad. Sci. U.S.A. 103, 11081-11085. doi: 10.1073/pnas.0602038103
Redinbaugh, M. G., and Campbell, W. H. (1991). Higher plant responses to environmental nitrate. Physiol. Plant. 82, 640-650. doi: 10.1111/j.1399-3054. 1991.tb02958.x

Remans, T., Nacry, P., Pervent, M., Filleur, S., Diatloff, E., Mounier, E., et al. (2006a). The Arabidopsis NRT1.1 transporter participates in the signaling pathway triggering root colonization of nitrate-rich patches. Proc. Natl. Acad. Sci. U.S.A. 103, 19206-19211. doi: 10.1073/pnas.0605275103

Remans, T., Nacry, P., Pervent, M., Girin, T., Tillard, P., Lepetit, M., et al. (2006b). A central role for the nitrate transporter NRT2.1 in the integrated morphological and physiological responses of the root system to nitrogen limitation in Arabidopsis. Plant Physiol. 140, 909-921. doi: 10.1104/pp.105. 075721

Richter, R., Behringer, C., Müller, I. K., and Schwechheimer, C. (2010). The GATAtype transcription factors GNC and GNL/CGA1 repress gibberellin signaling downstream from DELLA proteins and PHYTOCHROMEINTERACTING FACTORS. Genes Dev. 24, 2093-2104. doi: 10.1101/gad.594910

Ristova, D., Carré, C., Pervent, M., Medici, A., Kim, G. J., Scalia, D., et al. (2016). Combinatorial interaction network of transcriptomic and phenotypic responses to nitrogen and hormones in the Arabidopsis thaliana root. Sci. Signal. 9:rs13. doi: 10.1126/scisignal.aaf2768

Riveras, E., Alvarez, J. M., Vidal, E. A., Oses, C., Vega, A., and Gutierrez, R. A. (2015). The calcium ion is a second messenger in the nitrate signaling pathway of Arabidopsis. Plant Physiol. 169, 1397-1404. doi: 10.1104/pp.15.00961

Rubin, G., Tohge, T., Matsuda, F., Saito, K., and Scheible, W. R. (2009). Members of the $L B D$ family of transcription factors repress anthocyanin synthesis and affect additional nitrogen responses in Arabidopsis. Plant Cell 21, 3567-3584. doi: $10.1105 /$ tpc.109.067041

Ruffel, S., Krouk, G., Ristova, D., Shasha, D., Birnbaum, K. D., and Coruzzi, G. M. (2011). Nitrogen economics of root foraging: transitive closure of the nitratecytokinin relay and distinct systemic signaling for $\mathrm{N}$ supply vs. demand. Proc. Natl. Acad. Sci. U.S.A. 108, 18524-18529. doi: 10.1073/pnas.1108684108

Ruffel, S., Poitout, A., Krouk, G., Coruzzi, G. M., and Lacombe, B. (2016). Long-distance nitrate signaling displays cytokinin dependent and independent branches. J. Integr. Plant Biol. 58, 226-229. doi: 10.1111/jipb.12453

Sablowski, R., and Dornelas, M. C. (2014). Interplay between cell growth and cell cycle in plants. J. Exp. Bot. 65, 2703-2714. doi: 10.1093/jxb/ert354

Saito, H., Oikawa, T., Hamamoto, S., Ishimaru, Y., Kanamori-Sato, M., SasakiSekimoto, Y., et al. (2015). The jasmonate-responsive GTR1 transporter is required for gibberellin-mediated stamen development in Arabidopsis. Nat. Commun. 6:6095. doi: 10.1038/ncomms7095

Sakakibara, H. (2005). Cytokinin biosynthesis and regulation. Vitam. Horm. 72, 271-287. doi: 10.1016/S0083-6729(05)72008-2

Sakakibara, H. (2006). Cytokinins: activity, biosynthesis, and translocation. Annu. Rev. Plant Biol. 57, 431-449. doi: 10.1146/annurev.arplant.57.032905.105231

Schaller, G. E., Street, I. H., and Kieber, J. J. (2014). Cytokinin and the cell cycle. Curr. Opin. Plant Biol. 21, 7-15. doi: 10.1016/j.pbi.2014.05.01

Schauser, L., Wieloch, W., and Stougaard, J. (2005). Evolution of NIN-like proteins in Arabidopsis, rice, and Lotus japonicus. J. Mol. Evol. 60, 229-237. doi: 10.1007/ s00239-004-0144-2

Scheible, W., Morcuende, R., Czechowski, T., Fritz, C., Osuna, D., PalaciosRojas, N., et al. (2004). Genome-wide reprogramming of primary and secondary metabolism, protein synthesis, cellular growth processes, and the regulatory infrastructure of Arabidopsis in response to nitrogen. Plant Physiol. 136, 2483-2499. doi: 10.1104/pp.104.047019

Segonzac, C., Boyer, J. C., Ipotesi, E., Szponarski, W., Tillard, P., Touraine, B., et al. (2007). Nitrate efflux at the root plasma membrane: identification of an Arabidopsis excretion transporter. Plant Cell 19, 3760-3777. doi: 10.1105/tpc. 106.048173

Shen-Orr, S. S., Milo, R., Mangan, S., and Alon, U. (2002). Network motifs in the transcriptional regulation network of Escherichia coli. Nat. Genet. 31, 64-68. doi: $10.1038 /$ ng 881

Signora, L., De Smet, I., Foyer, C. H., and Zhang, H. (2001). ABA plays a central role in mediating the regulatory effects of nitrate on root branching in Arabidopsis. Plant J. 28, 655-662. doi: 10.1046/j.1365-313x.2001.01185.x

Simon, M. C., and Keith, B. (2008). The role of oxygen availability in embryonic development and stem cell function. Nat. Rev. Mol. Cell Biol. 9, 285-296. doi: $10.1038 / \mathrm{nrm} 2354$ 
Stitt, M. (1999). Nitrate regulation of metabolism and growth. Curr. Opin. Plant Biol. 2, 178-186. doi: 10.1016/S1369-5266(99)80033-8

Sugiura, M., Georgescu, M. N., and Takahashi, M. (2007). A nitrite transporter associated with nitrite uptake by higher plant chloroplasts. Plant Cell Physiol. 48, 1022-1035. doi: $10.1093 / \mathrm{pcp} / \mathrm{pcm} 073$

Sumimoto, H., Kamakura, S., and Ito, T. (2007). Structure and function of the PB1 domain, a protein interaction module conserved in animals, fungi, amoebas, and plants. Sci. STKE 2007:re6. doi: 10.1126/stke.4012007re6

Tabata, R., Sumida, K., Yoshii, T., Ohyama, K., Shinohara, H., and Matsubayashi, Y. (2014). Perception of root-derived peptides by shoot LRR-RKs mediates systemic N-demand signaling. Science 346, 343-346. doi: 10.1126/science. 1257800

Takei, K., Ueda, N., Aoki, K., Kuromori, T., Hirayama, T., Shinozaki, K., et al. (2004). AtIPT3 is a key determinant of nitrate-dependent cytokinin biosynthesis in Arabidopsis. Plant Cell Physiol. 45, 1053-1062. doi: 10.1093/pcp/pch119

Tal, I., Zhang, Y., Jorgensen, M. E., Pisanty, O., Barbosa, I. C. R., Zourelidou, M., et al. (2016). The Arabidopsis NPF3 protein is a GA transporter. Nat. Commun. 7:11486. doi: $10.1038 /$ ncomms 11486

Taochy, C., Gaillard, I., Ipotesi, E., Oomen, R., Leonhardt, N., Zimmermann, S., et al. (2015). The Arabidopsis root stele transporter NPF2.3 contributes to nitrate translocation to shoots under salt stress. Plant J. 83, 466-479. doi: $10.1111 /$ tpj.12901

Tian, Q. Y., Sun, P., and Zhang, W. H. (2009). Ethylene is involved in nitratedependent root growth and branching in Arabidopsis thaliana. New Phytol. 184, 918-931. doi: 10.1111/j.1469-8137.2009.03004.x

Tsang, J., Zhu, J., and van Oudenaarden, A. (2007). MicroRNA-mediated feedback and feedforward loops are recurrent network motifs in mammals. Mol. Cell 26, 753-767. doi: 10.1016/j.molcel.2007.05.018

Tsay, Y. F., Chiu, C. C., Tsai, C. B., Ho, C. H., and Hsu, P. K. (2007). Nitrate transporters and peptide transporters. FEBS Lett. 581, 2290-2300. doi: 10.1016/ j.febslet.2007.04.047

Tsay, Y. F., Schroeder, J. I., Feldmann, K. A., and Crawford, N. M. (1993). The herbicide sensitivity gene CHL1 of Arabidopsis encodes a nitrate-inducible nitrate transporter. Cell 72, 705-713. doi: 10.1016/0092-8674(93)90399-B

van Dam, T. J. P., Zwartkruis, F. J. T., Bos, J. L., and Snel, B. (2011). Evolution of the TOR Pathway. J. Mol. Evol. 73, 209-220. doi: 10.1007/s00239-011-9469-9

Vance, C. P. (2001). Symbiotic nitrogen fixation and phosphorus acquisition. Plant nutrition in a world of declining renewable resources. Plant Physiol. 127, 390-397. doi: 10.1104/pp.010331

Vanneste, S., and Friml, J. (2009). Auxin: a trigger for change in plant development. Cell 136, 1005-1016. doi: 10.1016/i.cell.2009.03.001

Vidal, E. A., Araus, V., Lu, C., Parry, G., Green, P. J., Coruzzi, G. M., et al. (2010). Nitrate-responsive miR393/AFB3 regulatory module controls root system architecture in Arabidopsis thaliana. Proc. Natl. Acad. Sci. U.S.A. 107, 4477-4482. doi: 10.1073/pnas.0909571107

Vidal, E. A., A'lvarez, J. M., Moyano, T. C., and Gutiérrez, R. A. (2015). Transcriptional networks in the nitrate response of Arabidopsis thaliana. Curr. Opin. Plant Biol 27, 125-132. doi: 10.1016/j.pbi.2015.06.010

Vidal, E. A., A'lvarez, J. M., and Gutiérrez, R. A. (2014a). Nitrate regulation of $A F B 3$ and NAC4 gene expression in Arabidopsis roots depends on NRT1.1 nitrate transport function. Plant Signal. Behav. 9:e28501. doi: 10.4161/psb. 28501

Vidal, E. A., Moyano, T. C., Canales, J., and Gutiérrez, R. A. (2014b). Nitrogen control of developmental phase transitions in Arabidopsis thaliana. J. Exp. Bot. 65, 5611-5618. doi: 10.1093/jxb/eru326

Vidal, E. A., Moyano, T. C., Riveras, E., Contreras-López, O., and Gutiérrez, R. A. (2013). Systems approaches map regulatory networks downstream of the auxin receptor AFB3 in the nitrate response of Arabidopsis thaliana roots. Proc. Natl. Acad. Sci. U.S.A. 110, 12840-12845. doi: 10.1073/pnas.1310937110

von der Fecht-Bartenbach, J., Bogner, M., Dynowski, M., and Ludewig, U. (2010). CLC-b-mediated NO3/H+ exchange across the tonoplast of Arabidopsis vacuoles. Plant Cell Physiol. 51, 960-968. doi: 10.1093/pcp/pcq062

von Wittgenstein, N. J., Le, C. H., Hawkins, B. J., and Ehlting, J. (2014). Evolutionary classification of ammonium, nitrate, and peptide transporters in land plants. BMC Evol. Biol. 14:11. doi: 10.1186/1471-2148-14-11

Walch-Liu, P., Filleur, S., Gan, Y., and Forde, B. G. (2005). Signaling mechanisms integrating root and shoot responses to changes in the nitrogen supply. Photosynth. Res. 83, 239-250. doi: 10.1007/s11120-004-2080-9
Wang, K. L., Li, H., and Ecker, J. R. (2002). Ethylene biosynthesis and signaling networks. Plant Cell 14(Suppl.), s131-s151. doi: 10.1105/tpc.001768

Wang, M., Zheng, Q., Shen, Q., and Guo, S. (2013). The critical role of potassium in plant stress response. Int. J. Mol. Sci. 14, 7370-7390. doi: 10.3390/ijms14047370

Wang, R., Guan, P., Chen, M., Xing, X., Zhang, Y., and Crawford, N. M. (2010). Multiple regulatory elements in the Arabidopsis NIA1 promoter act synergistically to form a nitrate enhancer. Plant Physiol. 154, 423-432. doi: $10.1104 /$ pp.110.162586

Wang, R., Guegler, K., LaBrie, S. T., and Crawford, N. M. (2000). Genomic analysis of a nutrient response in Arabidopsis reveals diverse expression patterns and novel metabolic and potential regulatory genes induced by nitrate. Plant Cell 12, 1491-1509. doi: 10.1105/tpc.12.8.1491

Wang, R., Liu, D., and Crawford, N. M. (1998). The Arabidopsis CHL1 protein plays a major role in high-affinity nitrate uptake. Proc. Natl. Acad. Sci. U.S.A. 95, 15134-15139. doi: 10.1073/pnas.95.25.15134

Wang, R., Okamoto, M., Xing, X., and Crawford, N. M. (2003). Microarray analysis of the nitrate response in Arabidopsis roots and shoots reveals over 1000 rapidly responding genes new linkages to glucose, trehalose-6-phosphate, iron, and sulfate metabolism. Plant Physiol. 132, 556-567. doi: 10.1104/pp.103. 021253

Wang, R., Tischner, R., Gutierrez, R. A., Hoffman, M., Xing, X., Chen, M., et al. (2004). Genomic analysis of the nitrate response using a nitrate reductasenull mutant of Arabidopsis. Plant Physiol. 136, 2512-2522. doi: 10.1104/pp.104. 044610

Wang, R., Xing, X., and Crawford, N. M. (2007). Nitrite acts as a transcriptome signal at micromolar concentrations in Arabidopsis roots. Plant Physiol. 145, 1735-1745. doi: 10.1104/pp.107.108944

Wang, R., Xing, X., Wang, Y., Tran, A., and Crawford, N. M. (2009). A genetic screen for nitrate regulatory mutants captures the nitrate transporter gene NRT1.1. Plant Physiol. 151, 472-478. doi: 10.1104/pp.109.140434

Wang, Y. Y., Hsu, P. K., and Tsay, Y. F. (2012). Uptake, allocation and signaling of nitrate. Trends Plant Sci. 17, 458-467. doi: 10.1016/j.tplants.2012.04.006

Wang, Y. Y., and Tsay, Y. F. (2011). Arabidopsis nitrate transporter NRT1.9 is important in phloem nitrate transport. Plant Cell 23, 1945-1957. doi: 10.1105/ tpc. 111.083618

Widiez, T., El Kafafi, E. S., Girin, T., Berr, A., Ruffel, S., Krouk, G., et al. (2011). HIGH NITROGEN INSENSITIVE 9 (HNI9)-mediated systemic repression of root NO3- uptake is associated with changes in histone methylation. Proc. Natl. Acad. Sci. U.S.A. 108, 13329-13334. doi: 10.1073/pnas.1017863108

Wilkinson, J. Q., and Crawford, N. M. (1991). Identification of the Arabidopsis CHL3 gene as the nitrate reductase structural gene NIA2. Plant Cell 3, 461-471. doi: $10.1105 /$ tpc.3.5.461

Wilkinson, J. Q., and Crawford, N. M. (1993). Identification and characterization of a chlorate resistant mutant of Arabidopsis with mutations in both NIA1 and NIA2 nitrate reductase structural genes. Mol. Gen. Genet. 239, 289-297. doi: $10.1007 / \mathrm{BF} 00281630$

Winter, D., Vinegar, B., Nahal, H., Ammar, R., Wilson, G. V., and Provart, N. J. (2007). An "electronic fluorescent pictograph" browser for exploring and analyzing large-scale biological data sets. PLOS ONE 2:e718. doi: 10.1371/ journal.pone. 0000718

Woodward, A. W., and Bartel, B. (2005). Auxin: regulation, action, and interaction. Ann. Bot. 95, 707-735. doi: 10.1093/aob/mci083

Xiao, L., and Grove, A. (2009). Coordination of ribosomal protein and ribosomal RNA gene expression in response to TOR signaling. Curr. Genomics 10, 198-205. doi: 10.2174/138920209788185261

Xiong, Y., McCormack, M., Li, L., Hall, Q., Xiang, C., and Sheen, J. (2013). GlucoseTOR signalling reprograms the transcriptome and activates meristems. Nature 496, 181-186. doi: 10.1038/nature12030

Xiong, Y., and Sheen, J. (2014). The role of target of rapamycin signaling networks in plant growth and metabolism. Plant Physiol. 164, 499-512. doi: 10.1104/pp. 113.229948

Xiong, Y., and Sheen, J. (2015). Novel links in the plant TOR kinase signaling network. Curr. Opin. Plant Biol. 28, 83-91. doi: 10.1016/j.pbi.2015.09.006

Xu, N., Wang, R., Zhao, L., Zhang, C., Li, Z., Lei, Z., et al. (2016). The Arabidopsis NRG2 protein mediates nitrate signaling and interacts with and regulates key nitrate regulators. Plant Cell 28, 485-504. doi: 10.1105/tpc.15.00567

Xuan, W., Beeckman, T., and Xu, G. (2017). Plant nitrogen nutrition: sensing and signaling. Curr. Opin. Plant Biol. 39, 57-65. doi: 10.1016/j.pbi.2017.05.010 
Yan, D., Easwaran, V., Chau, V., Okamoto, M., Ierullo, M., Kimura, M., et al. (2016). NIN-like protein 8 is a master regulator of nitrate-promoted seed germination in Arabidopsis. Nat. Commun. 7:13179. doi: 10.1038/ ncomms 13179

Zhang, H., and Forde, B. G. (1998). An Arabidopsis MADS box gene that controls nutrient-induced changes in root architecture. Science 279, 407-409. doi: $10.1126 /$ science. 279.5349 .407

Zhao, Y. (2012). Auxin biosynthesis: a simple two-step pathway converts tryptophan to indole-3-acetic acid in plants. Mol. Plant 5, 334-338. doi: $10.1093 / \mathrm{mp} / \mathrm{ssr} 104$

Zheng, D., Han, X., An, Y. I., Guo, H., Xia, X., and Yin, W. (2013). The nitrate transporter NRT2.1 functions in the ethylene response to nitrate deficiency in Arabidopsis. Plant Cell Environ. 36, 1328-1337. doi: $10.1111 /$ pce. 12062

Zhu, J. K. (2002). Salt and drought stress signal transduction in plants. Annu. Rev. Plant Biol. 53, 247-273. doi: 10.1146/annurev.arplant.53.091401.143329
Zoncu, R., Efeyan, A., and Sabatini, D. M. (2011). mTOR: from growth signal integration to cancer, diabetes and ageing. Nat. Rev. Mol. Cell Biol. 12, 21-35. doi: $10.1038 / \mathrm{nrm} 302$

Conflict of Interest Statement: The author declares that the research was conducted in the absence of any commercial or financial relationships that could be construed as a potential conflict of interest.

The reviewer EW and handling Editor declared their shared affiliation.

Copyright (๑) 2017 Guan. This is an open-access article distributed under the terms of the Creative Commons Attribution License (CC BY). The use, distribution or reproduction in other forums is permitted, provided the original author(s) or licensor are credited and that the original publication in this journal is cited, in accordance with accepted academic practice. No use, distribution or reproduction is permitted which does not comply with these terms. 